\title{
Role of circulating molecules in age-related cardiovascular and metabolic disorders
}

\author{
Yung Ting Hsiao ${ }^{1,2+}$, Ippei Shimizu ${ }^{1 *}$, Yohko Yoshida ${ }^{1,3}$ and Tohru Minamino 1,4*
}

\begin{abstract}
Studies analyzing heterochronic parabiosis mice models showed that molecules in the blood of young mice rejuvenate aged mice. Therefore, blood-based therapies have become one of the therapeutic approaches to be considered for age-related diseases. Blood includes numerous biologically active molecules such as proteins, metabolites, hormones, miRNAs, etc. and accumulating evidence indicates some of these change their concentration with chronological aging or age-related disorders. The level of some circulating molecules showed a negative or positive correlation with all-cause mortality, cardiovascular events, or metabolic disorders. Through analyses of clinical/translation/basic research, some molecules were focused on as therapeutic targets. One approach is the supplementation of circulating anti-aging molecules. Favorable results in preclinical studies let some molecules to be tested in humans. These showed beneficial or neutral results, and some were inconsistent. Studies with rodents and humans indicate circulating molecules can be recognized as biomarkers or therapeutic targets mediating their pro-aging or anti-aging effects. Characterization of these molecules with aging, testing their biological effects, and finding mimetics of young systemic milieu continue to be an interesting and important research topic to be explored.
\end{abstract}

Keywords: Parabiosis, Aging, Rejuvenation, Circulating molecules, Cardiovascular diseases

\section{Introduction}

The level of molecules in circulation including proteins, metabolites, hormones, miRNAs change with chronological aging, and studies with parabiosis, blood exchange, and plasma transfer indicated these mediate the "anti-aging" or "pro-aging" effect in systemic organs. Heterochronic parabiosis, a parabiotic pairing between young and old mice, showed exposure to a young systemic environment leads to the rejuvenation of aged progenitor cells [1]. Exposure of aged mice to young blood resulted in rejuvenating synaptic plasticity and enhancement in cognitive function [2]. Factors found in young blood induced neurogenic rejuvenation of brains

\footnotetext{
* Correspondence: ippeishimizu@yahoo.co.jp; t.minamino@juntendo.ac.jp;

t_minamino@yahoo.co.jp

${ }^{\dagger}$ Y ung Ting Hsiao and Ippei Shimizu contributed equally to this work.

1 Department of Cardiovascular Biology and Medicine, Juntendo University Graduate School of Medicine, 2-1-1 Hongo, Bunkyo-ku, Tokyo 113-8431,

Japan

Full list of author information is available at the end of the article
}

in aged mice and improved olfactory discrimination [3]. The heterochronic parabiosis model showed antigeronic factors promote vascular rejuvenation in aged mice through attenuation of oxidative stress, and suppression of endothelial dysfunction [4]. Conversely, old blood was shown to induce alteration in mitochondrial structure and function in young mice [5]. Exposure of young mice to plasma from old mice induced reduction in synaptic plasticity, declined spatial learning and memory [6]. Single heterochronic blood exchange resulted in rapid inhibition of multiple tissues by old blood [7]. Studies indicate molecules in circulation increase or reduce with aging and affect systemic homeostasis. We would like to delineate these in this review article.

\section{Main text \\ Role of circulating proteins or peptides in age-related disorders \\ Concentration of proteins or peptides in circulation changes with chronological aging, and this affects}

(c) The Author(s). 2022 Open Access This article is licensed under a Creative Commons Attribution 4.0 International License, which permits use, sharing, adaptation, distribution and reproduction in any medium or format, as long as you give appropriate credit to the original author(s) and the source, provide a link to the Creative Commons licence, and indicate if changes were made. The images or other third party material in this article are included in the article's Creative Commons licence, unless indicated otherwise in a credit line to the material. If material is not included in the article's Creative Commons licence and your intended use is not permitted by statutory regulation or exceeds the permitted use, you will need to obtain permission directly from the copyright holder. To view a copy of this licence, visit http://creativecommons.org/licenses/by/4.0/. 
homeostasis in cardiovascular system $[8,9]$. In this section, we will introduce these focusing on cardiovascularmetabolic disorders.

\section{Growth differentiation factors}

The aged heart is characterized by cardiomyocyte hypertrophy [10]. In non-obese, non-diabetic humans, the growth differentiation factor 11 (GDF11) level in circulation increased with aging and became highest in individuals aged 41-50. This declined thereafter and became lowest at age 71-80 [11]. GDF11 reversed age-related cardiomyocyte hypertrophy, indicating the role of this circulating protein in the suppression of cardiomyocyte hypertrophy [12]. GDF11 suppressed pathological myocardial remodeling in a murine diabetic cardiomyopathy model through the SIRT1 signaling pathway [13]. In vitro studies showed administration of GDF11 prevented hypertrophy in cultured neonatal rat ventricular myocytes treated with norepinephrine [14]. Another report showed this molecule mediated antiapoptotic effects in cardiomyocytes under hypoxic conditions through activation of autophagy [15]. GDF11 was also shown to improve endothelial dysfunction, inhibit endothelial apoptosis, and reduce atherosclerotic plaque in apolipoprotein E knockout (ApoE KO) mice [16]. Interestingly, a recent study showed cardiomyocyte-specific depletion of GDF11 (Myh6-Cre; Gdf11 floxed mice) did not result in cardiac hypertrophy but showed left ventricular dilatation [17]. It needs to be noted that in this paper, the level of GDF11 did not reduce in cardiac tissue possibly through the production of this molecule by noncardiomyocytes, and some other animal models should be generated and studied to test the role of GDF11 in cardiomyocytes as authors mentioned in this paper. Issues to be considered would be the potential side effect of GDF11 in skeletal muscle. GDF11 inhibited muscle regeneration and reduced satellite cell expansion in mice [18]. In the hindlimb ischemia model or Duchenne muscular dystrophy model mice, inhibition of GDF11 resulted in the enhancement of muscle hypertrophy and grip strength [19]. This indicated GDF11 suppression (not activation) may become a therapeutic target for sarcopenia. Studies indicate GDF11 mediates beneficial roles in cardiac tissues and detrimental effects in skeletal muscle; however, we also need to note that a high level of GDF11 $(5.0 \mathrm{mg} / \mathrm{kg})$ caused severe body weight loss, cachexia, and death [20]. Another report concluded introduction of GDF11 $(0.1 \mathrm{mg} / \mathrm{kg})$ had no effect on cardiac structure or function [21]. Together with the exploration of optimized concentration, further studies are needed to test the therapeutic potential of this protein in cardio-vascular metabolic disorders.

GDF15 is a stress-responsive cytokine having multiple and possibly bidirectional roles in pathogenic conditions.
Circulating GDF15 was reported to increase with aging in humans, and this inversely associated with active lifestyle [22], showed a positive correlation with signs of accelerated aging and all-cause mortality in aged individuals [23]. Elevation in GDF15 is associated with a reduction in muscle mass and strength in older patients at hospitalization [24]. GDF15 level predicted all-cause mortality in patients with heart failure [25]. The level of GDF15 in circulation was reported to predict 11-year mortality in older adults [26]. In patients with atrial fibrillation, GDF15 was a risk factor for major bleeding, stroke, and mortality [27]. GDF15 was also shown to be associated with various cardiovascular events in coronary heart diseases, heart failure, and atherosclerosis [28]. GDF15 was reported to have an equal diagnostic capability in heart failure with preserved ejection fraction (HFpEF) patients compared with $\mathrm{N}$-terminal pro-brain natriuretic peptide (NT-proBNP) [29]. Heart failure with reduced ejection fraction (HFrEF) patients had a higher level of this molecule in circulation compared with heart failure with midrange ejection fraction (HFmrEF) [29]. Controversies exist in the role of GDF15 in pathological conditions. In the heart, GDF15 is considered to mediate anti-inflammatory, anti-oxidative, and anti-apoptotic effects and mediated cardioprotective effects [30]. GDF15 ameliorated cardiac injury in the ischemia-reperfusion model [31]. In this paper, the authors also showed GDF15 suppressed apoptosis in cultured cardiomyocytes subjected to ischemia-reperfusion [31]. Generation of myocardial infarction in the GDF15 knockout (KO) model led to an increase in cardiac rupture in the $\mathrm{KO}$ group [32]. Mechanistically, GDF15 suppressed the infiltration of polymorphonuclear leukocytes into the infarcted myocardium, thereby suppression of this molecule led to this rupture-prone cardiac phenotype after ligation of the coronary artery [32]. In vitro studies showed GDF15 increased phosphorylation of TGF-betaactivated kinase1 (TAK1) in C2C12 cells, and the TAK1 inhibitor led to a reduction in the marker of muscle atrophy [33]. Senescent endothelial cells secreted GDF15 [34] and activated the ROS-mediated p16 signaling pathway [35]. The role of GDF15 may be context dependent, and further studies are needed to explore whether modulation of GDF15 becomes a therapy in some specific conditions.

\section{MMPs and their inhibitors}

Matrix metalloproteinases (MMPs) belong to a large family with zinc-dependent enzyme activity and are able to degrade the extracellular matrix. The negative endogenous regulators are tissue inhibitors of metalloproteinases (TIMPs). This directly binds to the catalytic domain of MMPs and suppresses their activity. Among them, the roles of MMP-2, MMP-9, TIMP-1, and 
TIMP-2 are extensively studied in atherosclerotic vascular disorders. In atherosclerotic lesions, MMP-2 and MMP-9 are considered to enhance leukocyte infiltration, vascular smooth muscle cell (VSMC) migration, and plaque formation and make plaque susceptible to rupture [36-42]. The level of MMP-2 and MMP-9 in circulation was higher in acute coronary syndrome (ACS) patients compared with stable angina patients [43]. Patients with peripheral arterial disease or intermittent claudication and critical ischemia had a high level of MMP-2, MMP-9, and TIMP-1 in circulation, and no change was observed in TIMP-2 expression [37, 38, 44]. Abdominal aortic aneurysm patients also exhibited high MMP-9 expression in circulation [45]. In the acute phase of aortic dissection (within $24 \mathrm{~h}$ of symptom onset), the level of MMP-1 and TIMP-1 in circulation became high, but MMP-2 and MMP-9 were similar compared with healthy individuals [46]. With aging, serum MMP-3 and TIMP-1 increased; in contrast, MMP-10 and TIMP-2 are reduced in humans [47]. This suggested changes in MMP/TIMP balance develop with aging. Studies indicate the level of MMPs and TIMPs would become biomarkers for cardiovascular disorders; however, further studies are needed to test whether they become direct therapeutic targets (please also see the following review article [48]).

\section{Inflammatory cytokines}

Level of pro-inflammatory cytokines such as interleukin6 (IL-6), IL-1 $\beta$, tumor necrosis factor $\alpha$ (TNF- $\alpha$ ), and Creactive protein $(\mathrm{CRP})$, molecules contributing to the enhancement of inflammation including soluble intercellular adhesion molecule-1 (ICAM-1), and vascular cell adhesion molecule-1 (VCAM-1) increase in circulation with chronological aging [49-52]. Chronic low-grade sterile inflammation associates with the production of reactive oxygen species (ROS), mitochondrial dysfunction, and cellular senescence and promotes pathologies in cardiovascular-metabolic disorders [8, 53]. The level of CRP in circulation is a most established marker for atherosclerotic vascular diseases [54-57]. A high CRP level in the blood was reported to be an independent risk factor for myocardial infarction (MI) [58] and predicted poor outcome in peripheral arterial disease (PAD) patients $[54,59]$. CRP is a powerful tool for risk prediction but in general not considered a therapeutic target [60]. The serum concentration of IL-6 increases with age [52], and this cytokine is also recognized as a marker for cardiovascular disease. In humans, the elevated level of IL-6 is associated with higher cardiovascular mortality $[61,62]$. Interestingly, IL-6 showed a more consistent and stronger predictive value than other inflammatory molecules in patients with PAD [8]. The level of TNF- $\alpha$ in circulation increased with aging [52], and the concentration of this cytokine in plasma showed a positive correlation with pro-atherogenic cytokine levels in atherosclerotic plaque of patients subjected to carotid surgery [63]. Plasma TNF- $\alpha$ elevated in post-myocardial infarction patients at increased risk for recurrent coronary events [64]. High circulating TNF- $\alpha$ is associated with increased mortality in patients with HFrEF or HFpEF [65]. TNF- $\alpha$ was reported to stimulate endothelial permeability, increase endothelial adhesion molecules, and promote inflammation in vessels $[66,67]$. TNF- $\alpha$ was also shown to induce insulin resistance and inhibit endothelium-dependent vasodilation in humans [68]. The pacing-induced dog heart failure model showed suppression of TNF- $\alpha$ ameliorated cardiac dysfunction by improving mitochondrial function and inhibiting ROS production [69]. The therapeutic potential of TNF- $\alpha$ was tested in clinical studies. A TNF- $\alpha$ antagonist, adalimumab, suppressed inflammation in the ascending aorta and carotids and decreased CRP by $51 \%$ in psoriasis patients [70]. Adalimumab was also shown to improve endothelial function and arterial stiffness in patients with severe psoriasis [71]. In rheumatoid arthritis patients, another TNF- $\alpha$ antagonist, infliximab, improved endothelial function [72]. Infliximab was tested in HFrEF patients, and this study concluded infliximab did not improve the clinical condition of moderatesevere heart failure at 28 week follow up period [73]. In healthy individuals, aging was shown to increase IL- $1 \beta$ in circulation [52]. Canakinumab, an IL-1 $\beta$ neutralizing antibody, significantly reduced cardiovascular events together with reduction in circulating CRP and IL- 6 at the follow-up [74]. In patients with prior myocardial infarction, canakinumab administration resulted in dosedependent reduction in hospitalization for heart failure [75]. Residual inflammatory risk was reported to relate to both IL-18 and IL- 6 after IL- $1 \beta$ inhibition, and IL-18 and IL- 6 are considered to be important therapeutic targets [76]. Serum soluble VCAM-1 (sVCAM-1) but not soluble ICAM-1 (sICAM-1) was shown to have a positive correlation with aging [77]. Studies showed high expression of circulating sVCAM-1 [78, 79] or sICAM-1 $[79,80]$ in PAD patients. In preclinical studies testing mice, blocking ICAM-1 suppressed angiotensin II (AngII)-induced cardiac remodeling [81]. Further studies are needed to test whether targeting VCAM-1 and ICAM-1 becomes a therapy for age-related diseases.

\section{Angiotensin II}

Angiotensin II (Ang-II) is the main bioactive product of the renin-angiotensin-aldosterone system (RAAS), and contributes for the activation of Ang II type 1 receptor (AT1R) mediated pathogenic signaling [82]. RAAS is considered to become activated in vessels and cardiac tissues of humans and rodents with aging [83]. This 
leads to an increase in ROS level together with inflammation in these organs and enhanced tissue remodeling $[84,85]$. Administration of an ACE inhibitor, enalapril, suppressed age-associated increases in cardiomyocyte apoptosis and mitochondrial ROS level [85]. The genetic model with AT1R depletion led to phenotype with longevity [86]. In a normotensive rat, the plasma Ang-II level was shown to increase with age [87], however, Ang-II was not shown to increase in plasma with aging in healthy human volunteers [88]. Considering RAAS activation develops with aging and promotes tissue remodeling in cardiovascular system, suppression of this pathway continues to be important targets in cardiovascular disorders.

\section{Osteocalcin}

Osteocalcin $(\mathrm{OC})$ is a vitamin $\mathrm{K}$-dependent protein which is produced by osteoblasts. This is secreted when insulin binds to osteoblasts in the presence of vitamin K, and can be recognized as a marker for bone remodeling $[89,90]$. Level of OC in circulation shows interesting behavior with aging. Both in male and female individuals, this decreased with aging from 20 to 49 years old [91]. In male, no significant correlation was observed after 50 years old [91]. In female, after showing age-dependent decline till 49 years old, serum OC markedly increased at age 50 years, and thereafter again started to decrease with aging [91]. A systematic meta-analysis concluded an inverse associations of circulating OC with risk of atherosclerotic outcomes and cardiovascular disease (CVD) endpoints [92]. An increase in OC is associated with lower pulse wave velocity (PWV) in aged diabetic male patients but this was not observed in female patients [93, 94]. In mice, OC administration improved hippocampal-dependent memory [95], and exercise capacity [96]. Another study showed OC prevents agerelated muscle loss in mice [97]. Total OC (tOC) have two primary forms, including undercarboxylated osteocalcin (ucOC) and carboxylated osteocalcin ( $\mathrm{COC}$ ), with distinct functions in each form. Aging was shown to be associated with the U-shaped pattern for $\mathrm{tOC}, \mathrm{cOC}$, and ucOC levels. The ucOC/tOC ratio was higher; in contrast, the $\mathrm{cOC} / \mathrm{tOC}$ ratio was lower in men with advanced age [98]. Some studies showed ucOC was a main bioactivity form of $\mathrm{OC}$, contributing to the regulation in glucose homeostasis and energy metabolism [99, 100]. Another study showed ucOC improved microvascular insufficiency and myocardial dysfunction in a rat diabetic cardiomyopathy model [101]. However, the following studies have challenged these findings by showing no endocrine abnormalities in OC-deficient mice [102, 103]. In humans, higher ucOC is associated with lower pulse wave velocity (PWV), but administration of this molecule in rabbits did not result in alteration of vasoactivity of carotid arteries [104]. Focusing on the specific form of OCs, further studies are needed to test the therapeutic potential of these molecules in agerelated diseases.

\section{Meteorin-like}

Meteorin-like is an adipokine, highly expressed in white adipose tissue. In patients with coronary artery disease (CAD), the level of Meteorin-like showed a negative correlation with the severity of CAD [105]. Some papers analyzing type 2 diabetic patients showed Meteorin-like elevated in circulation [105-109]. Other papers showed newly diagnosed type 2 diabetes patients had a significantly lower level of Meteorin-like in circulation [110, 111]. And recently published meta-analysis concluded no significant change in circulating Meteorin-like was observed in patients with diabetes [112]. Low serum Meteorin-like is associated with glucose intolerance, endothelial dysfunction, and atherosclerosis [105-108]. A study with rodents showed increasing Meteorin-like in circulation enhanced energy expenditure and improved glucose tolerance in mice [113]. This molecule also improved glucose tolerance in skeletal muscles [114]. Systemic depletion of Meteorin-like decreased blood HDL cholesterol and increased triglyceride in blood [115]. Doxorubicin-induced cardiotoxicity was suppressed with Meteorin-like through the activation of cAMP/PKA/SIRT1 signaling [116]. Meteorin-like also suppressed pancreatic $\beta$-cell apoptosis and promoted proliferation of this cell [117]. Meteorin-like was reported to enhance skeletal muscle repair, indicating this molecule has roles for muscle regeneration [118]. Preclinical studies indicate the protective role of this molecule in cardiovascular metabolic disorders and further studies are needed to analyze the level of this molecule in aging and test whether Meteorin-like can mediate favorable effects in humans.

\section{Mesencephalic astrocyte-derived neurotrophic factor}

Mesencephalic astrocyte-derived neurotrophic factor (MANF) is a secreted stress-response protein, and the level of this protein was reported to decline with aging in flies, mice, and humans [119]. MANF overexpression resulted in the extension of the life span in flies, and heterozygous depletion resulted in the progression of liver damage and fibrosis, and supplementation of this molecule improved age-related metabolic dysfunction [119]. Overexpression of MANF in the liver resulted in suppression of adipose inflammation, improved insulin sensitivity, and hepatic steatosis [120]. In contrast, liverspecific MANF depletion exacerbated obesity, insulin resistance, and hepatic steatosis [120]. MANF had critical roles for pancreatic $\beta$-cell proliferation [121] and protected human pancreatic beta cells against stress- 
induced cell death [122]. This molecule contributed to the protection of neuronal apoptosis in a rat model of intracerebral hemorrhage [123]. MANF suppressed ischemia-reperfusion mediated cell death in the heart [124]. A recent report showed MANF knockdown increased cardiac damage after ischemia-reperfusion in the heart, and this was reversed by MANF overexpression [125]. Further studies would be needed to test whether MANF administration mediates favorable effects in humans.

\section{Fibroblast growth factor 21}

Fibroblast growth factor 21 (FGF21) is a member of fibroblast growth factor (FGF), and circulating FGF21 is considered mainly produced in the liver. Patients with coronary artery disease exhibiting a high serum FGF21 level had a greater risk of developing major adverse cardiovascular events (MACEs) [126]. FGF21 increased in nonalcoholic fatty liver disease patients [127]. In healthy individuals, circulating FGF21 increased with aging [128]. Interestingly, FGF21 in circulation reduced with endurance exercise in the elderly [129], and the level of this protein was low in healthy centenarians [130]. Compared with young individuals ( $<40$ years), FGF21 was high in elderly individuals ( $>70$ years); however, FGF21 responsiveness in adipose tissue was similar, and this suggested the presence of FGF21-resistant state with aging [131]. FGF21 stimulates glucose uptake in adipocytes, and FGF21 transgenic mice became resistant to diet-induced obesity [132]. FGF21 administration ameliorated age-related metabolic disorders including insulin resistance, dyslipidemia, and obesity in rodents [132, 133]. FGF21 extended the lifespan in mice, and this was considered through blunting the growth hormone/insulin-like growth factor-1 signaling pathway in the liver [134]. In the aged mice, FGF21 was reported to prevent low-protein diet-induced renal inflammation [135] and promoted remyelination in the central nervous system [136]. To further test the role of FGF21, PEGylated FGF21 was administrated in humans with obesity and diabetes predisposed to fatty liver [137]. HbA1c showed no change, but metabolic parameters and fibrosis markers improved with administration of this compound [137]. Biological effects of a variant of FGF21, LY2405319, were tested in patients with obesity and diabetes [138]. LY2405319 treatment resulted in a significant improvement in dyslipidemia, and this was associated with favorable effects on body weight, fasting insulin, and adiponectin [138]. Another FGF21 mimetic, PF-05231023, was tested in humans by single intravenous injection to test safety and tolerability, and the study concluded this compound as safe [139]. Enhancement of FGF21-mediated signaling continues to be an interesting approach.

\section{Activin A}

Activin A belongs to a TGF- $\beta$ superfamily and is known to mediate its biological effect through activin type II receptor (ActRII) signaling. Serum Activin A was reported to increase with aging [140]. This molecule was also reported to show dose-dependent association with metabolic syndrome [141] or diabetes and correlated positively with carotid intima-media thickness in prediabetes individuals [142]. Patients with diabetic kidney disease had a higher level of Activin A in circulation, and this showed a positive correlation with reduced kidney function [143]. Non-alcoholic steatohepatitis (NASH) patients were also reported to have high expression of this protein in circulation [144]. Mice aged 28 months had around a 3-fold increase in the Activin A level compared with 4-month-old mice, and this was considered to activate ActRII signaling in the aged heart [145]. They also showed the Activin A level in the blood increased with left ventricle pressure overload, and overexpression of this molecule induced cardiac dysfunction in young mice [145]. GDF11 is another ligand for ActRII contributing to the activation of this receptor. As already demonstrated, several reports showed the cardio-protective role of GDF11 in the suppression of age-related cardiomyocyte hypertrophy [12], or myocardial remodeling in diabetic mice [13]. In the same report by Roh et al., GDF11 was shown to activate ActRII signaling in the heart and reduced cardiac function [145]. The same group showed pharmacological suppression of ActRII ameliorated cardiac dysfunction in a murine left ventricle pressure overload model [145]. Anti-Activin A therapy was introduced in humans with a monoclonal antibody describing Garetosmab, and no critical safety issue was raised [146]. Further studies would show whether targeting Activin A would become a therapy for cardiovascular-metabolic diseases.

\section{Insulin and insulin-like growth factor-1}

Insulin or insulin-like growth factor-1 (IGF-1) binds to insulin receptor or IGF-1 receptor and mediate their biological effects through nearly identical downstream signaling. With aging, the circulating-insulin level in response to oral glucose load declined [147]. Aging is considered to be associated with relative insulin secretory defects, and together with the reduction in the clearance of this molecule, the level of insulin is considered similar between young and aged individuals [148]. The genetic model showed a reduction in circulating insulin by $\sim 25 \%$ improved systemic insulin resistance and extended the lifespan in mice [149]. Homozygous depletion of insulin receptor in cardiomyocytes resulted in cardiac dysfunction in mice [150], but heterozygous depletion was cardioprotective in the murine model with left ventricle pressure overload [151]. Insulin resistance predicted risk 
for heart failure, and the murine model with heart failure indicated systemic insulin resistance, a state of hyperinsulinemia, developed with left ventricle pressure overload. Insulin resistance developed in the liver and visceral white adipose tissue, but cardiac insulin signaling continued to be enhanced, and excessive insulin signaling mediated detrimental effects through induction of pathological cardiac hypertrophy and ischemia in heart $[151,152]$. Aging associated with an increase in cardiac insulin signaling, and this was reported as pathogenic by suppressing autophagy [153]. Insulin needs to be maintained on a physiological level, and too little or too much of this signaling is considered to become pathogenic in cardiac tissue $[154,155]$. Serum IGF-1 level increased till 15 years old in both genders and thereafter declined with aging [156]. High IGF-1 predicted mortality and morbidity risk [157], and similar to insulin, studies with rodents indicated the importance of maintaining IGF-1-mediated signaling at a physiological level. IGF-1 depletion resulted in cerebro-microvascular dysfunction and deficit in spatial memory test [158]. Liver-specific depletion of IGF-1 led to dysregulation in antioxidant responses in the vasculature [159], but this model ameliorated aging-induced hepatic injury [160]. Heterozygous depletion of IGF-1 resulted in a 33\% increase in lifespan in 129Sv-background mice [161]. Akt is a downstream signaling molecule for both insulin receptor and IGF-1 receptor, and constitutive activation of this molecule in cardiomyocytes enhanced cardiac hypertrophy and induced systolic dysfunction [162]. In contrast, skeletal muscle-specific overexpression of Akt induced skeletal muscle hypertrophy, together with a reduction in body weight in mice fed a high-calorie diet [163]. Insulin/IGF-1-mediated signaling has bidirectional roles and needs to be regulated in specific cells or organs to minimize detrimental effects in organs including the heart.

\section{Growth hormone}

Growth hormone $(\mathrm{GH})$ is essential for physiological growth and has roles in lipid metabolism, body fat distribution, inflammation, and vascular health [164, 165]. Patients with GH deficiency have higher BMI and risk of dyslipidemia, therefore prone to develop hypertension and an increase in carotid intima media thickness [164, 166]. The level of $\mathrm{GH}$ in circulation reaches a maximum level in adolescence, and thereafter declines with aging [51]. The therapeutic potential of GH was tested in clinical trials. These showed increased muscle mass, reduction in body fat, improvement in skin elasticity, and reduction in bone demineralization, but were not associated with the enhancement of strength and functional capacity [167-171]. Issues were raised against adverse effects reported with $\mathrm{GH}$ administration. $\mathrm{GH}$ treatment is associated with carpal tunnel syndrome, arthralgias, glucose intolerance, and diabetes [168]. GH treatment was also shown to increase cancer risk [172]. For these reasons, administration of $\mathrm{GH}$ to individuals for the purpose of delaying aging and rejuvenation has become illegal and unethical in the USA [173].

\section{Oxytocin}

Oxytocin is a hormone produced mainly in the hypothalamus and secreted by the pituitary gland [174]. In humans, the level of this hormone is reduced in circulation in both genders $[175,176]$, and a high serum oxytocin level is positively associated with logical memory in aged females [176]. In male mice, aging led to a reduction of this hormone in plasma, and administration of oxytocin improved muscle regeneration through the activation of muscle stem cell activation and proliferation [177]. Oxytocin and two analogs reversed insulin resistance and glucose intolerance in obese mice [178]. A 4week oxytocin treatment contributed to reducing body weight in obese humans [178]. Oxytocin also promoted liver regeneration especially in aged mice possibly through the activation of autophagic response [179]. Intranasal administration of oxytocin for 10 days was reported as safe in the aged population [180], and whether this mediates beneficial effects in individuals with cardiovascular-metabolic diseases remains an open question to be explored.

\section{Role of circulating steroid hormone and vitamins in age- related disorders}

Circulating steroid hormones and vitamins have critical roles in the maintenance of homeostasis. In this section, we focus on the roles of steroid hormone (testosterone), vitamin $\mathrm{D}$, and vitamin $\mathrm{K}$.

\section{Testosterone}

Testosterone is the most important androgen affecting the male reproductive system. The level of testosterone reduces with chronological aging [181] and reported to show an inverse association with adverse cardiovascular outcomes, diabetes, mortality, and New York Heart Association class in heart failure [182-186]. Testosterone replacement is used in clinical settings [187]; however, in older individuals with a diminished level of this hormone, it still remains unclear whether a supply of this hormone mediates protective effect for the cardiovascular system [188]. Older men administrated with testosterone showed an increase in cardiovascular adverse events [189]. Among aged men with a reduction in circulating testosterone level, treatment with testosterone for 1 year significantly increased noncalcified plaque volume in coronary arteries [188]. Testosterone replacement therapy did not improve clinical symptoms, left 
ventricular ejection fraction, and $\mathrm{N}$-terminal pro-B-type natriuretic peptide level in patients with heart failure [190], but another report showed this improved functional capacity and symptoms in men with advanced heart failure [191]. Administration of testosterone in aged men with low testosterone level did not lead to an improvement in memory and cognitive function in 1 year [192] and showed no benefit in vitality or walking distance [193]. Another paper reported testosterone replacement for 3 years associated with improvements in stair-climbing power, muscle mass, and power [194]. Results of clinical studies are conflicting [195], and future studies are needed to test whether replacement of this hormone becomes therapies for specific clinical conditions in selected subtypes.

\section{Vitamin D}

The level of vitamin $\mathrm{D}$ in circulation reduces with aging, and this is considered a healthcare issue to be treated $[196,197]$. Vitamin D deficiency is associated with an increase in the prevalence of diabetes, hypertension, dyslipidemia, and peripheral artery disease [198]. A reduction in serum vitamin $D$ is linked with left ventricular hypertrophy and impairment in myocardial performance [199]. Low vitamin D level is associated with dilated cardiomyopathy, and vitamin D concentration showed a negative correlation with left ventricle end- diastolic or systolic dimension [200]. Animal studies showed cardiomyocyte-specific depletion of vitamin D receptor results in cardiac hypertrophy [201]. Many clinical studies testing the therapeutic potential of vitamin $D$ could not show a beneficial effect. Administration of vitamin $\mathrm{D}$ to prediabetic individuals did not reduce the risk of diabetes [202]. Vitamin D treatment did not show effects in systolic or diastolic blood pressure, physical performance, and cognitive function [203, 204]. This treatment failed to show benefit on lower extremity function and was associated with an increased risk of falls [205]. Taking oral vitamin D did not reduce blood pressure or left ventricular hypertrophy in patients with hypertension [206]. These studies indicate supplementation of vitamin $\mathrm{D}$ is not sufficient to mediate beneficial biological effects in humans.

\section{Vitamin $K$}

Vitamin $K$ is a family of naphthoquinone compounds and includes vitamin K1 (phylloquinone) and K2 (menaquinone). Vitamin $\mathrm{K} 1$ is the predominant form in the diet. Vitamin K2 is synthesized by bacteria and included in food where bacteria are involved in the production process. Low phylloquinone level in circulation is associated with an increase in the risk of all-cause mortality [207] and is linked with higher CVD risk in aged individuals treated for hypertension [208]. Plasma

Table 1 The dynamics, clinical or pre-clinical evidence, and biological effect of circulating proteins or peptides in aging and agerelated disorders

\begin{tabular}{|c|c|c|c|}
\hline Circulating molecules & Clinical or pre-clinical evidence in aging and aging-related disorders & Biological effect & Ref. \\
\hline GDF11 & Increased with aging till 50 years old, and thereafter declined in humans & Conditional & $11-21$ \\
\hline GDF 15 & Increased with aging in humans & Conditional & $22-35$ \\
\hline MMP-2, MMP-9 & Higher in ACS compared with stable angina patients & $\mathrm{N} / \mathrm{T}$ & 43 \\
\hline MMP-2, MMP-9, TIMP-2 & Higher in PAD patients & $\mathrm{N} / \mathrm{T}$ & $37,38,44$ \\
\hline MMP-9 & Higher in abdominal aortic aneurysm patients & $\mathrm{N} / \mathrm{T}$ & 45 \\
\hline MMP-1, TIMP-1 & Became high in patients with acute phase of aortic dissection & $\mathrm{N} / \mathrm{T}$ & 46 \\
\hline $\begin{array}{l}\text { MMP-3, TIMP-1 } \\
\text { MMP-10, TIMP-2 }\end{array}$ & MMP-3 and TIMP-1 increased, and MMP-10 and TIMP-2 reduced in humans with aging & $\mathrm{N} / \mathrm{T}$ & 47 \\
\hline CRP & Increased in atherosclerotic vascular diseases & Pro-aging & $54-57$ \\
\hline IL-6 & Increased in humans with aging, and predicted cardiovascular mortality & $\mathrm{N} / \mathrm{T}$ & $52,61,62$ \\
\hline TNF- $\alpha$ & Increased in humans with aging, associated with increased mortality in $\mathrm{HFpEF}$ or HFrEF patients & Pro-aging & $52,63-73$ \\
\hline IL-1 $\beta$ & Increased in humans with aging & Pro-aging & $52,74,75$ \\
\hline sVCAM-1 & Increased in humans with aging & $\mathrm{N} / \mathrm{T}$ & 77 \\
\hline sVCAM-1 & Increased in PAD patients & $\mathrm{N} / \mathrm{T}$ & $78-79$ \\
\hline sICAM-1 & Increased in PAD patients & Pro-aging & $79-81$ \\
\hline Ang-II & Increased in normotensive rat with aging & $\mathrm{N} / \mathrm{T}$ & 87 \\
\hline Ang-II & No change with aging in healthy human volunteers & $\mathrm{N} / \mathrm{T}$ & 88 \\
\hline $\mathrm{OC}$ & $\begin{array}{l}\text { Decreased with aging in both genders from } 20 \text { to } 49 \text { years old. No significant correlation in males after } 50 \text { years old, } \\
\text { but in females markedly increased at age } 50 \text { years and thereafter decreased with aging }\end{array}$ & Anti-aging & $91-97$ \\
\hline Meteorin-like & No significant change in patients with diabetes & Anti-aging & $112-118$ \\
\hline MANF & Reduced with aging in flies, mice and humans & Anti-aging & $119-125$ \\
\hline FGF-21 & Increased in healthy individuals with aging & Anti-aging & $128,132-139$ \\
\hline Activin A & Increased in humans with aging & Pro-aging & 140,145 \\
\hline Activin A & Increased in patients with NASH & Pro-aging & 144,145 \\
\hline Insulin & Relative insulin secretory defects and reduction in the clearance is considereed to develop with aging & Conditional & $\begin{array}{l}147-155,162, \\
163\end{array}$ \\
\hline IGF-1 & IGF-1 level increased till 15 years old in both genders, and thereafter declined with aging in humans & Conditional & $156-163$ \\
\hline $\mathrm{GH}$ & Reached maximum level in adolescence, and thereafter declined with aging in humans & Conditional & $51,164-173$ \\
\hline Oxytocin & Reduced in both genders in humans with chronological aging & Anti-aging & $175-180$ \\
\hline
\end{tabular}


Table 2 The dynamics, clinical or pre-clinical evidence, and biological effect of circulating steroid hormone and vitamins in aging and age-related disorders

\begin{tabular}{|c|c|c|c|}
\hline Circulating molecules & Clinical or pre-clinical evidence in aging and age-related disorders & Biological effect & Ref \\
\hline Testosterone & Reduced with chronological aging in humans & Conditional & $181-195$ \\
\hline Vitamin D & Reduced with aging in humans & Anti-aging & $196-206$ \\
\hline Vitamin K1 & Low Vitamin $\mathrm{K} 1$ level associated with an increase in risk of all-cause mortality and CVD risk in humans & Anti-aging & $207-214$ \\
\hline
\end{tabular}

phylloquinone is inversely associated with IL-6 and CRP [209], and high vitamin $\mathrm{K}$ is linked with a lower level of inflammatory markers and diminished risk of type 2 diabetes [210-212]. Systemic review and meta-analysis concluded vitamin $\mathrm{K}$ supplementation reduced vascular calcification but not vascular stiffness [213], and vitamin $\mathrm{K} 1$ administration was also shown to slow down the progression of aortic valve calcification [214]. Vitamin K2 treatment reduced the risk of diabetes [215], but this could not improve vascular stiffness, as analyzed with pulse wave velocity, in patients with chronic kidney disease (CKD) [216]. Another report showed vitamin K2 supplementation could not stop the progression of arterial calcification in patients with diabetes and cardiovascular disease [217].

Epigenome-wide associated study revealed a strong correlation between the epigenomic signatures of phylloquinone baseline status and response to supplementation, and further studies would show specific groups that would show a favorable response against vitamin $\mathrm{K}$ supplementation [218].

\section{Role of circulating miRNAs in age-related disorders microRNA}

MicroRNAs (miRs) are small non-coding RNAs produced by cells. They are engulfed in extracellular vesicles (EVs) and mediate paracrine and endocrine biological effects in local as well as remote organs. In the circulation of elderly healthy individuals, the level of miR-126-3p increased, and the concentration of this miR became low in patients with poor glycemic control [219]. Senescent human umbilical vein endothelial cells (HUVECs) were shown to secrete a high level of miR-126-3p in the conditioned medium, and authors described this $\mathrm{miR}$ as an active component of senescence-associated secretory phenotype (SASP) [219]. Administration of miR-126-3p mimics to $\mathrm{ApoE}^{-/-}$mice suppressed atherogenesis, and antagomir-126-3p partially reversed the protective effect of $17 \beta$-estradiol in athrosclerosis [220]. Activation of miR-126-3p production was shown to play a key role in the reduction of vascular calcification [221]. The miR-30c increased with age in humans [222] and reduced in patients with coronary heart disease [223]. This $\mathrm{miR}$ reduced with diabetes and became lowest in coronary heart disease patients with diabetes [223]. The c-miR-21-5p level increased till 80 years old, thereafter became low in centenarians compared with 80 year-old healthy subjects, and low level of this miR is considered beneficial for longevity [224]. Several other miRNAs are reported to increase or decrease with aging or age-related diseases, and these are described in the following review articles [225, 226]. Some of these miRs would become useful as a biomarker and may become therapeutic targets with less off-target effects, and further studies are needed to test this.

\section{Conclusion and discussion}

Accumulating evidence indicate exposure of aged mice to young blood results in rejuvenation. The fundamental question is whether this is applicable in humans. Given that molecules in circulation of young individuals have potential to reverse aging phenotype, the PLASMA (Plasma for Alzheimer Symptom Amelioration) study was designed for patients with Alzheimer's diseases. In this randomized clinical trial, plasma was collected from donors aged 18 to 30 years and injected into patients with Alzheimer's diseases. Outcomes concluded this procedure as safe, tolerable, and feasible

Table 3 The dynamics, clinical or pre-clinical evidence, and biological effect of circulating miRNAs in aging and age-related disorders

\begin{tabular}{|c|c|c|c|}
\hline Circulating molecules & Clinical or pre-clinical evidence in aging and age-related disorders & Biological effect & Ref \\
\hline $\operatorname{miR}-126-3 p$ & Increased in elderly healthy human & Anti-aging & 219-221 \\
\hline miR-126-3p & Low in patients with poor glycemic control & Anti-aging & 219-221 \\
\hline $\operatorname{miR}-30 \mathrm{c}$ & Increased in humans with aging & $\mathrm{N} / \mathrm{T}$ & 222 \\
\hline $\operatorname{miR}-30 \mathrm{c}$ & Reduced in patients with coronary heart disease and/or diabetes & $\mathrm{N} / \mathrm{T}$ & 223 \\
\hline c-miR-21-5p & Increased till 80 years old, thereafter became low in centenarians & $\mathrm{N} / \mathrm{T}$ & 224 \\
\hline
\end{tabular}


Table 4 Tested molecules in circulation, phenotype of organs in rodents, and potential clinical application

\begin{tabular}{|c|c|c|c|}
\hline Tested molecules & Phenotype of organs in rodents & Potential clinical application & Ref. \\
\hline GDF11 & Heart; GDF11 administration reduced age-related cardiac hypertrophy and increased diastolic function. & GDF11 may improve heart failure & 12 \\
\hline GDF11 & $\begin{array}{l}\text { Heart; Myocardial GDF11 overexpression suppressed cardiac dilatation in diabetic mice, and protected against oxidative stress and } \\
\text { cardiomyocyte apoptosis. }\end{array}$ & GDF11 may improve heart failure & 13 \\
\hline GDF11 & Artery; GDF 11 overexpression reduced atherosclerotic lesions. & GDF11 may improve atherosclerotic diseases & 16 \\
\hline GDF11 & Heart; GDF11 administration did not change the level of cardiac hypertrophy and diastolic function in 24-month-old male mice. & N/A & 21 \\
\hline GDF11 & Heart; GDF11 administration significantly reduced cardial hypertrophy and improved systolic function in TAC mice. & GDF11 may improve heart failure & 20 \\
\hline GDF11 & Skeletal muscle; GDF11 administration inhibited muscle regeneration. & GDF11 may exacerbate sarcopenia & 18 \\
\hline GDFI1 & $\begin{array}{l}\text { Skeletal muscle; Systemic GDF11 suppression increased skeletal muscle mass in dystrophic mdx mice and improved grip strength and } \\
\text { motor coordination. }\end{array}$ & GDF11 may exacerbate sarcopenia & 19 \\
\hline GDF15 & Heart; Gdf15 deficient mice exhibited greater infarct size with permanent coronary artery ligation. & GDF15 may improve ischemic heart disease & 31 \\
\hline GDF15 & Heart; Gdf15 deficient mice showed rupture-prone cardiac phenotype with permanent coronary artery ligation. & GDF15 may improve ischemic heart disease & 32 \\
\hline CRP & Heart; CRP promote infection and aggravate the disease process in acute MI mice. & CRP may exacerbate heart failure & 58 \\
\hline TNF- $\alpha$ & $\begin{array}{l}\text { Heart; Increased circulating TNF- } \alpha \text { in pacing dog increased LV dysfunction by a local impairment in mitochondrial function and } \\
\text { increase in oxidative stress and myocyte apoptosis. }\end{array}$ & $\mathrm{TNF}-\alpha$ may exacerbate heart failure & 69 \\
\hline sICAM-1 & $\begin{array}{l}\text { Heart; ICAM-1 blocking mice prevents ANG II-induced cardiac remodeling via modulating adhesion and migration of LFA-1 } \\
\text { positive monocytes }\end{array}$ & sICAM-1 may exacerbate hypertensive cardiac diseases & 81 \\
\hline $\mathrm{OC}$ & Skeletal muscle; $O C$ administration prevented age-related muscle loss. & OC may improve sarcopenia & 97 \\
\hline $\mathrm{OC}$ & Brain; OC administration improved hippocampal-dependent memory. & OC may improve cognitive function & 95 \\
\hline $\mathrm{OC}$ & Skeletal muscle; OS administration enhanced the exercise capacity. & OC may improve sarcopenia & 96 \\
\hline ucOC & Heart; ucOC administration decreased myocardial fibrosis. & OC may improve heart failure & 101 \\
\hline Meteorin-like & Subcutaneous adipose tissue; Meteorin-like administration enhanced beiging. & Meteorin-like may suppress obesity & 113 \\
\hline Meteorin-like & Skeletal muscle; Meteorin-like administration improved glucose tolerance. & Meteorin-like may suppress obesity & 114 \\
\hline Meteorin-like & Skeletal muscle; Meteorin-like administration resulted in an increase in satellite cell proliferation and improved injured muscle repair. & Meteorin-like may improve muscle repair & 118 \\
\hline MANF & Liver; MANF heterozygous knoockout mice promoted liver damage, fibrosis, and steatosis. & MANF may improve liver damage & 119 \\
\hline MANF & $\begin{array}{l}\text { Adipose tissue and liver; Liver-specific Manf overexpression indietary obese mice promoted browning of iWAT, reduced BW, } \\
\text { improved insulin sensitivity and hepatic steatosis. }\end{array}$ & MANF may suppress obesity and its comorbidities & 120 \\
\hline MANF & Brain; MANF improved neurological functions after intracerebral hemorrhage. & MANF may improve neurological functions after intracerebral hemorrhage. & 123 \\
\hline MANF & Heart; MANF suppressed I/R-mediated cell death in heart. & MANF may suppress ischemic heart disease & 124,125 \\
\hline FGF-21 & Plasma; FGF-21 reduced plasma glucose and triglycerides in genetic obese models. & FGF-21 may improve obesity and diabetes & 132 \\
\hline FGF-21 & Life span; FGF-21 overexpression extended lifespan and increased insulin sensitivity & FGF-21 may lead to longevity & 134 \\
\hline FGF-21 & Kidney; FGF-21 protected renal damage and inflammation. & FGF-21 may improve kidney dysfunction & 135 \\
\hline FGF-21 & Central nervous system (CNS); FGF-21 promoted the proliferation of oligodendrocyte precursor cells (OPCs) and CNS regeneration. & FGF-21 may improve CNS disorders & 136 \\
\hline Activin A & Heart; Activin A reduced both systolic and diastolic cardiac function. & Activin A may exacerbate heart failure & 145 \\
\hline Oxytocin & Skeletal muscle; Oxytocin improved muscle regeneration by enhancing aged muscle stem cell activation/proliferation. & Oxytocin may improve sarcopenia & 177 \\
\hline Oxytocin & Liver; Oxytocin promoted liver regeneration in aged mice. & Oxytocin may improve liver damage in aging & 179 \\
\hline Insulin & Life span; Insulin suppression extended lifespan. & Insulin may promote aging & 149 \\
\hline Insulin & Heart; Homozygous depletion of insulin receptor in cardiomyocytes resulted in cardiac dysfunction. & Complete depletion of insulin receptor mediated signaling enhances heart failure & 150 \\
\hline Insulin & Heart; Heterozygous depletion of insulin receptor in cardiomyocytes became cardioprotective in LV pressure overload mice model. & Suppression of excessive cardiac insulin signaling may become cardioprotective & 151 \\
\hline IGF-1 & Brain; Neural stem cell IGF-1 receptor-deficient mice exhibited enhanced neurogenesis and olfactory function & Suppression of IGF-1 receptor in neural stem cell may enhance olfactory function & 158 \\
\hline IGF-1 & Artery; Liver specific IGF-1 depletion increased oxidative stress and induced endothelial cell dysfunction. & IGF-1 may improve endothelial function & 159 \\
\hline Vitamin D & Heart; Cardiac vitamin D receptor depletion induced cardiac hypertrophy, but did not enhance interstitial fibrosis. & Vitamin D may improve heart failure & 201 \\
\hline miR-126-3p & Artery; miR-126-3p mimics reduced atherosclerotic lesions in $\mathrm{ApoE}-/-$ mice. & miR-126-3p may improve atherosclerotic diseases & 220 \\
\hline miR-126-3p & Artery; miR-126-3p reduced atherosclerotic lesions in $\mathrm{ApoE}-/-$ mice. & miR-126-3p may improve atherosclerotic diseases & 221 \\
\hline
\end{tabular}

Table 5 Tested molecules in circulation, findings of clinical studies, and clinical application

\begin{tabular}{|c|c|c|c|}
\hline Tested molecules & Findings of clinical studies & Clinical application & Ref. \\
\hline$\frac{T N F-\alpha}{T}$ & Introduction of TNF- $a$ reduced insulin induced glucose uptake in forarms of lean healthy male volunteers. & TNF-a inhibition ameliorates systemic insulin resistance in obesity and/or diabetes. & 68 \\
\hline TNF- $a$ & Anti-TNF- $a$ antibody, adalimumab, reduced circulating hs-CRP levels in patients with psoriasis. & TNF- $\alpha$ inhibition ameliorates atherosclerotic diseases in patients with psoriasis. & 70 \\
\hline TNF- $\alpha$ & Anti-TNF- $a$ antibody, adalimumab, improved endothelial function and arterial stiffness in patients with psoriasis. & TNF- $\alpha$ inhibition ameliorates atherosclerotic diseases in patients with psoriasis. & 71 \\
\hline TNF- $\alpha$ & Anti-TNF- $a$ antibody, infliximab, improved endothelial function in patients with rheumatoid arthritis. & TNF-a inhibition ameliorates atherosclerotic diseases in patients with rheumatoid arthritis. & 72 \\
\hline TNF- $\alpha$ & Anti-TNF- $a$ antibody, infliximab, could not improve clinical status in HFrFF. & TNF- $\alpha$ may not become a druggable target for $\mathrm{HFrEF}$. & 73 \\
\hline $\mathrm{LL}-1 \beta$ & $\begin{array}{l}\text { Anti-IL-1B antibody, canakinumab, suppressed nonfatal myocardial inflarction, noffatal stroke, cardiovascular death, or hospitalization for unstable } \\
\text { angina that led to urgent revascularization. }\end{array}$ & IL-1 $\beta$ inhibition ameliorates atherosclerotic diseases. & 74 \\
\hline IL-1B & Anti-IL-I antibody, canakinumab, reduced hospitalization for heart fallure in patients with prior myocardial infarction exhibiting elevation in hs-CRP. & IL-1B inhibition ameliorates heart fallure in patients with prior myocardial infarction with high hs-CRP. & 75 \\
\hline FGF-21 & Recombinant PEGylated human FGF-21, pegbelfermin, improved dyslipidemia in patients with obesity and type2 diabetes. & FGF-21 may ameliorate dyslipidemia in paticnts with obesity and type2 diabetes. & 137 \\
\hline FGF-21 & An FGF21 analog, PF-05231023, dose dependently reduced triglyceride in patients with type2 diabetes. & FGF-21 may ameliorate dyslipidemia in patients with type2 diabetes. & 139 \\
\hline Activin A & $\begin{array}{l}\text { Anti-activin A antibody, garetosmab, was administrated into patients with fibrodysplasia ossificans progressiva, and serious safety issues were not } \\
\text { raised. }\end{array}$ & Further studies are needed to test whether activin $\mathrm{A}$ inhibition becomes a therapy for fibrodysplasia ossificans progressiva. & 146 \\
\hline $\mathrm{GH}$ & GH could not augment muscle strengh or hypertrophy in healthy elderly men. & GH administration may not become a therapy for sarcopenia. & 167 \\
\hline GH & rhGH impaired oral glucose tolerance and reduced insulin sensitivity, but was otherwise well tolerated. & Further studies are needed to test whether GH administration becomes a therapy for sarcopenia. & 169 \\
\hline $\mathrm{GH}$ & $\begin{array}{l}\text { GH increased lean body mass and decreased fat mass, however, the adverse effects were frequent. Effects for muscle strengh co-admininstrated with sex } \\
\text { steroid varied betwecn genders. }\end{array}$ & $\begin{array}{l}\text { GH administration may enhance skeletal muscle strengh in male, but this associated with high prevalance for diabetes and } \\
\text { glucosc intolerance. }\end{array}$ & 168 \\
\hline $\mathrm{GH}$ & GH increased lean tissue mass and decreased fat mass. Side effects occurred frequently. & GH improved body composition, but functional ability of skeletal muscle did not improve. & 170 \\
\hline Testosterone & Testosterone increased coronary artery noncalifified plaque volume among older men with symptomatic hypogonadism. & Testosterone may promote pathologies in coronary artery discases. & 188 \\
\hline Testosterone & Testosterone did not improve clinical symptoms and functional capacity in heart failure patients with reduced jection fraction. & Testosterone administration may not become a therapy for heart failure with reduced jection fraction. & 190 \\
\hline Testosterone & Testosterone improved functional capacity and symptoms in men with moderately severe heart fallure. & Testosterone administration may become a therapy for heart failure with reduced ejection fraction. & 191 \\
\hline Testosterone & Testosterone improved stair-climbing power, muscle mass, and power. & Testosterone administration may become a therapy for sarcopenia. & 194 \\
\hline Vitamin D & Vitamin D3 supplementation did not reduce the risk of diabetes than placebo. & Vitamin D3 administration would not become a therapy for diabetes. & 202 \\
\hline Vitamin D & Vitamin $\mathrm{D}$ did not prevent physiological function declinc. & Vitamin D administration may not improve physiological function. & 204 \\
\hline Vitamin D & Vitamin D3 showed no benefit on lower extremity function. & Vitamin D3 administration may not become a therapy for sarcopenia. & 205 \\
\hline Vitamin D & $\begin{array}{l}\text { Vitamin D3 could not reduce cholesterol or glucose level, and did not reduce blood pressure or left venticular mass in patients with resistant } \\
\text { hypertension. }\end{array}$ & Vilamin D3 administration may not become a therapy for lifestyle-related diseases. & 206 \\
\hline Vitamin $\mathrm{K}$ & Vitamin $\mathrm{K}$ reduced vascular calcification $(\mathrm{VC})$ but not vascular stiffness (VS). & $\begin{array}{l}\text { Vitamin } \mathrm{K} \text { adminisistration may become a therapy for cardiovascular disorders, and further studics are needed to test this } \\
\text { hypoothesis. }\end{array}$ & 213 \\
\hline Vitamin $\mathrm{K}$ & Vitamin $\mathrm{K}$ decelerated the progression of artic valve calcification. & Vitamin $\mathrm{K}$ administration may become a therapy for caclific aortic stenosis. & 214 \\
\hline Vitamin $\mathrm{K}$ & Both vitamin $\mathrm{K} 1$ and $\mathrm{K} 2$ intakes associated with a reduced risk of type 2 diabctes. & This is a prospective cohort study and further studies are necded to tess the potential rolc of vitamin $\mathrm{K}$ in diabetes. & 215 \\
\hline Vitamin $\mathrm{K}$ & Vitamin $\mathrm{K} 2$ supplementation did not ameliorate vascular stiffesess in patients with $\mathrm{CKD}$. & Vitamin K2 administration may not lead to vascular health in patients with $\mathrm{CKD}$. & 216 \\
\hline Vitamin $\mathrm{K}$ & Vitamin $\mathrm{K} 2$ supplementation did not reduce arterial calcification in patients with type 2 diabetes with a history of cardiovascular disease. & Vitamin $\mathrm{K} 2$ administration may not suppress arterial calcification in patients with tested background. & 217 \\
\hline
\end{tabular}




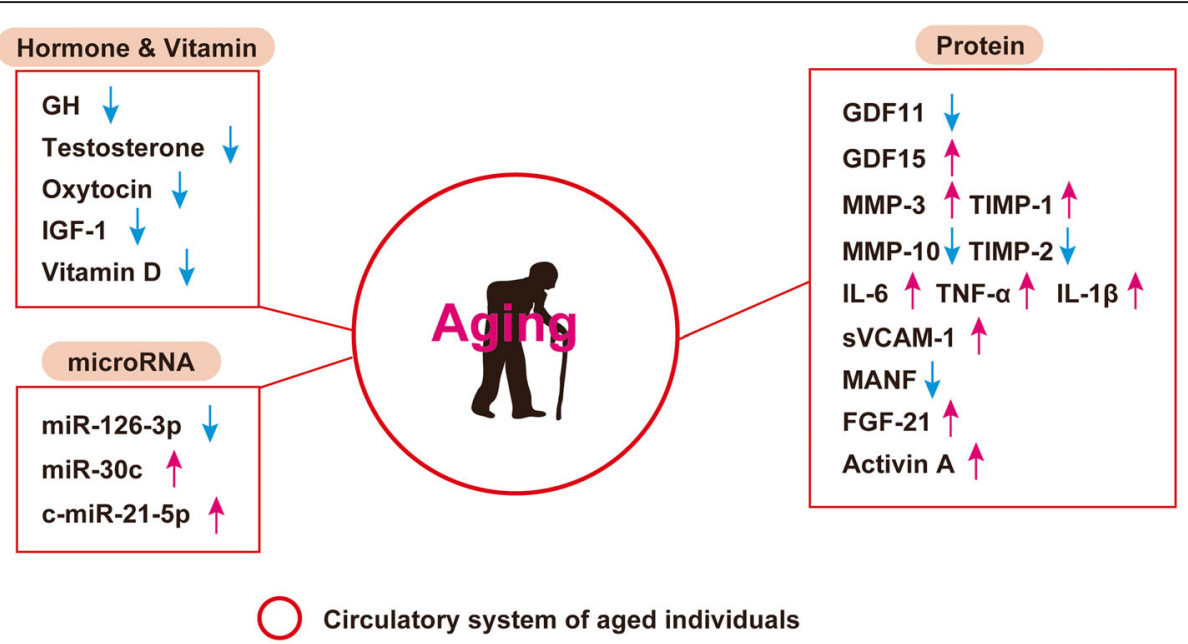

Fig. 1 Concentration of hormones, vitamins, proteins, and microRNAs changes with chronological aging, and these are described in the figure. Growth differentiation factor (GDF), matrix metalloproteinase (MMP), tissue inhibitor of metalloproteinases (TIMP), interleukin (IL), tumor necrosis factor a (TNF-a), soluble vascular cell adhesion molecule-1(sVCAM-1), mesencephalic astrocyte-derived neurotrophic factor (MANF), fibroblast growth factor 21 (FGF-21), growth hormone (GH), insulin-like growth factor-1 (IGF-1)

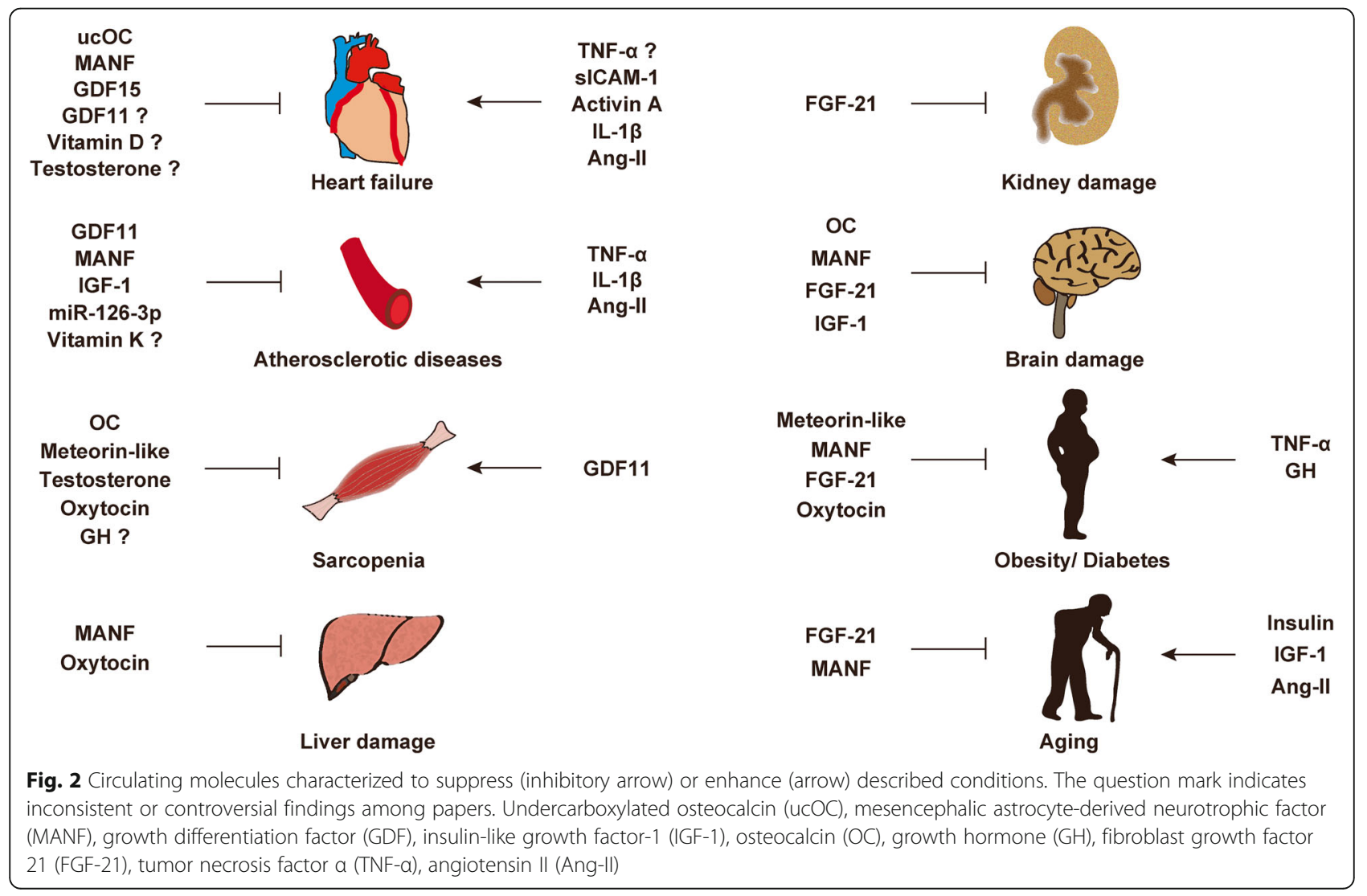




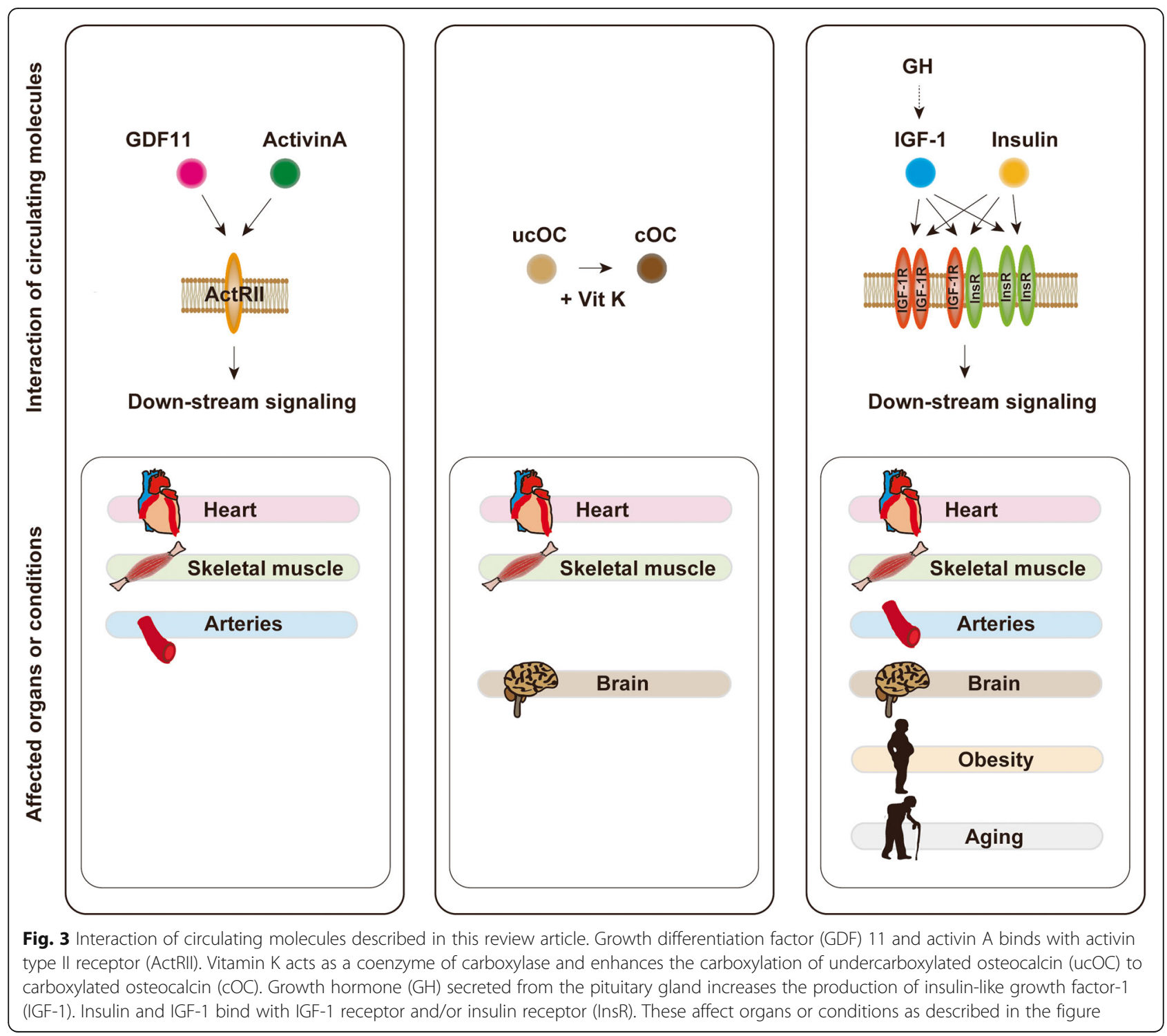

[227]. In 2017, a California-based start-up company named Ambrosia began selling transfusions of young plasma for 8000USD per liter. The US Food and Drug Administration cautioned this because no proven clinical benefit has so far been demonstrated in humans, and now this start-up is completely closed [228]. This approach engulfs ethical issues, and limitation of biological materials and potential risk of transmission of known and unknown viral infection are other issues to be considered. Blood includes series of biologically active molecules such as proteins, metabolites, hormones, miRNAs, etc. In this review article, we introduced some of these fluctuate with chronological aging. They can be categorized as pro-aging or anti-aging molecules, and studies showed inhibition or activation of these molecules resulting in beneficial/detrimental/neutral effects in rodents or humans (Tables 1, 2, 3, 4, and 5;
Figs. 1 and 2). Several circulating molecules are reported to interact with each other, and analyzing known or unknown interactions is essential to comprehensively understand their biological effects (Fig. 3). Levels of metabolites in circulation would also change with aging or age-related disorders [229, 230], but we did not describe these in our review article. Recent findings showed aged hematopoietic stem cells are refractory to rejuvenation through exposure to young blood [231]. Exposure to a youthful circulation did not reverse the diminished osteochondrogenic activity of skeletal stem cells [232]. These studies indicate some cells are resistant against rejuvenation. Finding mimetics of young systemic milieu, and exploration of rejuvenating factors for specific refractory cells, continues to be an interesting and important approach to find next-generation therapies for age-related disorders. 


\section{Acknowledgements}

Not applicable.

\section{Authors' contributions}

YH, IS, YY and TM wrote the manuscript. IS and TM supervised the manuscript preparation. All authors read and approved the manuscript.

\section{Funding}

Not applicable.

\section{Availability of data and materials}

Not applicable.

\section{Declarations}

Ethics approval and consent to participate

Not applicable.

\section{Consent for publication}

All authors agreed to publish this paper.

\section{Competing interests}

YH, IS, YY and TM have nothing to declare related with this manuscript.

\section{Author details}

${ }^{1}$ Department of Cardiovascular Biology and Medicine, Juntendo University Graduate School of Medicine, 2-1-1 Hongo, Bunkyo-ku, Tokyo 113-8431, Japan. ${ }^{2}$ Institute for Diseases of Old Age, Juntendo University Graduate School of Medicine, Tokyo 113-8431, Japan. ${ }^{3}$ Department of Advanced Senotherapeutics, Juntendo University Graduate School of Medicine, Tokyo 113-8431, Japan. ${ }^{4}$ Japan Agency for Medical Research and Development-Core Research for Evolutionary Medical Science and Technology (AMED-CREST), Japan Agency for Medical Research and Development, Tokyo 100-0004, Japan.

Received: 16 September 2021 Accepted: 30 November 2021 Published online: 10 January 2022

\section{References}

1. Conboy IM, et al. Rejuvenation of aged progenitor cells by exposure to a young systemic environment. Nature. 2005:433(7027):760-4.

2. Villeda SA, et al. Young blood reverses age-related impairments in cognitive function and synaptic plasticity in mice. Nat Med. 2014;20(6):659-63.

3. Katsimpardi $\mathrm{L}$, et al. Vascular and neurogenic rejuvenation of the aging mouse brain by young systemic factors. Science. 2014;344(6184):630-4.

4. Kiss T, et al. Circulating anti-geronic factors from heterochonic parabionts promote vascular rejuvenation in aged mice: transcriptional footprint of mitochondrial protection, attenuation of oxidative stress, and rescue of endothelial function by young blood. Geroscience. 2020;42(2):727-48.

5. Gonzalez-Armenta JL, et al. Heterochronic Parabiosis: Old Blood Induces Changes in Mitochondrial Structure and Function of Young Mice. J Gerontol A Biol Sci Med Sci. 2021;76(3):434-9

6. Villeda $S A$, et al. The ageing systemic milieu negatively regulates neurogenesis and cognitive function. Nature. 2011;477(7362):90-4.

7. Rebo J, et al. A single heterochronic blood exchange reveals rapid inhibition of multiple tissues by old blood. Nat Commun. 2016;7:13363.

8. Saenz-Pipaon G, et al. The Role of Circulating Biomarkers in Peripheral Arterial Disease. Int J Mol Sci. 2021:22(7).

9. O'Neill S, et al. Blood-Based Biomarkers for Metabolic Syndrome. Trends Endocrinol Metab. 2016;27(6):363-74.

10. Triposkiadis F, Xanthopoulos A, Butler J. Cardiovascular Aging and Heart Failure JACC Review Topic of the Week. J Am Coll Cardiol. 2019;74(6):80413.

11. Anon-Hidalgo J, et al. Circulating GDF11 levels are decreased with age but are unchanged with obesity and type 2 diabetes. Aging (Albany NY). 2019; 11(6):1733-44

12. Loffredo FS, et al. Growth differentiation factor 11 is a circulating factor that reverses age-related cardiac hypertrophy. Cell. 2013;153(4):828-39.

13. Zhu HZ, et al. GDF11 Alleviates Pathological Myocardial Remodeling in Diabetic Cardiomyopathy Through SIRT1-Dependent Regulation of Oxidative Stress and Apoptosis. Front Cell Dev Biol. 2021;9.
14. Garrido-Moreno V, et al. GDF-11 prevents cardiomyocyte hypertrophy by maintaining the sarcoplasmic reticulum-mitochondria communication. Pharmacol Res. 2019;146.

15. Jiao $L$, et al. GDF11 replenishment protects against hypoxia-mediated apoptosis in cardiomyocytes by regulating autophagy. Eur J Pharmacol. 2020;885

16. Johnen $\mathrm{H}$, et al. Increased expression of the TGF-b superfamily cytokine MIC-1/GDF15 protects ApoE(-/-) mice from the development of atherosclerosis. Cardiovasc Pathol. 2012;21(6):499-505.

17. Garbern J, et al. Analysis of Cre-mediated genetic deletion of Gdf11 in cardiomyocytes of young mice. Am J Phys Heart Circ Phys. 2019;317(1): H201-12.

18. Egerman MA, et al. GDF11 Increases with Age and Inhibits Skeletal Muscle Regeneration. Cell Metab. 2015;22(1):164-74.

19. Jin Q, et al. A GDF11/myostatin inhibitor, GDF11 propeptide-Fc, increases skeletal muscle mass and improves muscle strength in dystrophic mdx mice. Skelet Muscle. 2019:9.

20. Harper SC, et al. GDF11 Decreases Pressure Overload-Induced Hypertrophy, but Can Cause Severe Cachexia and Premature Death. Circ Res. 2018. 123(11):1220-31.

21. Smith SC, et al. GDF11 Does Not Rescue Aging-Related Pathological Hypertrophy. Circ Res. 2015;117(11):926-32.

22. Conte M, et al. GDF15 Plasma Level Is Inversely Associated With Level of Physical Activity and Correlates With Markers of Inflammation and Muscle Weakness. Front Immunol. 2020;11.

23. Tavenier J, et al. Association of GDF15 With Inflammation and Physical Function During Aging and Recovery After Acute Hospitalization: A Longitudinal Study of Older Patients and Age-Matched Controls. J Gerontol A Biol Sci Med Sci. 2021;76(6):964-74.

24. Herpich C, et al. Associations Between Serum GDF15 Concentrations, Muscle Mass, and Strength Show Sex-Specific Differences in Older Hospital Patients. Rejuvenation Res. 2021;24(1):14-9.

25. Kempf T, et al. Prognostic utility of growth differentiation factor-15 in patients with chronic heart failure. J Am Coll Cardiol. 2007:50(11):1054-60.

26. Daniels $L B$, et al. Growth-Differentiation Factor-15 is a Robust, Independent Predictor of 11-Year Mortality Risk in Community-Dwelling Older Adults The Rancho Bernardo Study. Circulation. 2011;123(19):2101-10.

27. Wallentin, L., et al., Growth Differentiation Factor 15, a Marker of Oxidative Stress and Inflammation, for Risk Assessment in Patients With Atrial Fibrillation Insights From the Apixaban for Reduction in Stroke and Other Thromboembolic Events in Atrial Fibrillation (ARISTOTLE) Trial. Circulation, 2014. 130(21): p. 1847-+.

28. Wollert KC, Kempf T, Wallentin L. Growth Differentiation Factor 15 as a Biomarker in Cardiovascular Disease. Clin Chem. 2017;63(1):140-51.

29. Li J, et al. Additional Diagnostic Value of Growth Differentiation Factor-15 (GDF-15) to N-Terminal B-Type Natriuretic Peptide (NT-proBNP) in Patients with Different Stages of Heart Failure. Med Sci Monit. 2018;24:4992-9.

30. Rochette L, et al. GDF15 and Cardiac Cells: Current Concepts and New Insights. Int J Mol Sci. 2021:22(16).

31. Kempf $\mathrm{T}$, et al. The transforming growth factor-beta superfamily member growth-differentiation factor-15 protects the heart from ischemia/ reperfusion injury. Circ Res. 2006;98(3):351-60.

32. Kempf T, et al. GDF-15 is an inhibitor of leukocyte integrin activation required for survival after myocardial infarction in mice. Nat Med. 2011;17(5): 581-U101.

33. Garfield BE, et al. Growth/differentiation factor 15 causes TGFbeta-activated kinase 1-dependent muscle atrophy in pulmonary arterial hypertension. Thorax. 2019;74(2):164-76.

34. Schafer MJ, et al. The senescence-associated secretome as an indicator of age and medical risk. Jci Insight. 2020:5(12).

35. Park $\mathrm{H}$, et al. GDF15 contributes to radiation-induced senescence through the ROS-mediated p16 pathway in human endothelial cells. Oncotarget. 2016;7(9):9634-44.

36. Sabry $\mathrm{M}$, et al. Matrix metalloproteinase 9 a potential major player connecting atherosclerosis and osteoporosis in high fat diet fed rats. PLoS One. 2021;16(2):e0244650.

37. Signorelli SS, et al. Patients with unrecognized peripheral arterial disease (PAD) assessed by ankle-brachial index (ABI) present a defined profile of proinflammatory markers compared to healthy subjects. Cytokine. 2012; 59(2):294-8. 
38. Signorelli SS, et al. Plasma Levels of Inflammatory Biomarkers in Peripheral Arterial Disease: Results of a Cohort Study. Angiology. 2016; 67(9):870-4

39. Pasterkamp G, et al. Atherosclerotic arterial remodeling and the localization of macrophages and matrix metalloproteases 1,2 and 9 in the human coronary artery. Atherosclerosis. 2000;150(2):245-53.

40. Wang C, et al. Apelin induces vascular smooth muscle cells migration via a PI3K/Akt/FoxO3a/MMP-2 pathway. Int J Biochem Cell Biol. 2015;69:173-82.

41. Kuzuya M, et al. Effect of MMP-2 deficiency on atherosclerotic lesion formation in apoE-deficient mice. Arterioscler Thromb Vasc Biol. 2006;26(5): $1120-5$

42. Luttun $\mathrm{A}$, et al. Loss of matrix metalloproteinase-9 or matrix metalloproteinase-12 protects apolipoprotein E-deficient mice against atherosclerotic media destruction but differentially affects plaque growth. Circulation. 2004;109(11):1408-14.

43. Zeng $B$, et al. Elevated circulating levels of matrix metalloproteinase- 9 and-2 in patients with symptomatic coronary artery disease. Intern Med J. 2005; 35(6):331-5

44. Tayebjee $\mathrm{MH}$, et al. Abnormal circulating levels of metalloprotease 9 and its tissue inhibitor 1 in angiographically proven peripheral arterial disease: relationship to disease severity. J Intern Med. 2005;257(1):110-6.

45. Takagi $\mathrm{H}$, et al. Circulating matrix metalloproteinase-9 concentrations and abdominal aortic aneurysm presence: a meta-analysis. Interact Cardiovasc Thorac Surg. 2009;9(3):437-40.

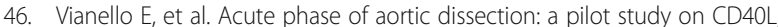
MPO, and MMP-1, $-2,9$ and TIMP-1 circulating levels in elderly patients. Immun Ageing. 2016;13:9.

47. Komosinska-Vassev K, et al. Age- and Gender-Dependent Changes in Connective Tissue Remodeling: Physiological Differences in Circulating MMP-3, MMP-10, TIMP-1 and TIMP-2 Level. Gerontology. 2011;57(1):44-52.

48. Cabral-Pacheco GA, et al. The Roles of Matrix Metalloproteinases and Their Inhibitors in Human Diseases. Int J Mol Sci. 2020:21(24).

49. Kaur N, et al. Mechanisms and Therapeutic Prospects of Diabetic Cardiomyopathy Through the Inflammatory Response. Front Physiol. 2021; 12:694864.

50. Hanna A, Frangogiannis NG. Inflammatory Cytokines and Chemokines as Therapeutic Targets in Heart Failure. Cardiovasc Drugs Ther. 2020;34(6):849-63.

51. Rybtsova N, et al. Can Blood-Circulating Factors Unveil and Delay Your Biological Aging? Biomedicines. 2020;8(12)

52. Alvarez-Rodriguez $\mathrm{L}$, et al. Aging is associated with circulating cytokine dysregulation. Cell Immunol. 2012;273(2):124-32.

53. Kumric $M$, et al. Circulating Biomarkers Reflecting Destabilization Mechanisms of Coronary Artery Plaques: Are We Looking for the Impossible? Biomolecules. 2021;11(6).

54. Saenz-Pipaon G, et al. Functional and transcriptomic analysis of extracellular vesicles identifies calprotectin as a new prognostic marker in peripheral arterial disease (PAD). J Extracell Vesicles. 2020;9(1):1729646.

55. Moutachakkir $\mathrm{M}$, et al. Immunoanalytical characteristics of $\mathrm{C}$-reactive protein and high sensitivity C-reactive protein. Ann Biol Clin (Paris). 2017;75(2):225-9.

56. Norja S, et al. C-reactive protein in vulnerable coronary plaques. J Clin Pathol. 2007:60(5):545-8.

57. Noren Hooten $\mathrm{N}$, et al. Association of oxidative DNA damage and C-reactive protein in women at risk for cardiovascular disease. Arterioscler Thromb Vasc Biol. 2012;32(11):2776-84.

58. Liu $Y$, et al. Study on the interaction mechanism between C-reactive protein and platelets in the development of acute myocardial infarction. Ann Transl Med. 2021;9(12):1012.

59. Akkoca M, et al. Role of microcirculatory function and plasma biomarkers in determining the development of cardiovascular adverse events in patients with peripheral arterial disease: a 5-year follow-up. Anatol J Cardiol. 2018; 20(4):220-8.

60. Ridker PM. From C-reactive protein to interleukin-6 to interleukin-1 moving upstream to identify novel targets for atheroprotection. Circ Res. 2016; 118(1):145-56

61. Zhang B, et al. Interleukin- 6 as a predictor of the risk of cardiovascular disease: a meta-analysis of prospective epidemiological studies. Immuno Investig. 2018;47(7):689-99.

62. Sarwar N, et al. Interleukin-6 receptor pathways in coronary heart disease: a collaborative meta-analysis of 82 studies. Lancet. 2012;379(9822):1205-13.
63. Edsfeldt A, et al. Circulating cytokines reflect the expression of proinflammatory cytokines in atherosclerotic plaques. Atherosclerosis. 2015, 241(2):443-9.

64. Ridker PM, et al. Elevation of tumor necrosis factor-alpha and increased risk of recurrent coronary events after myocardial infarction. Circulation. 2000; 101(18):2149-53.

65. Dunlay SM, et al. Tumor necrosis factor-alpha and mortality in heart failure: a community study. Circulation. 2008;118(6):625-31.

66. Mattila $\mathrm{P}$, et al. TNF alpha-induced expression of endothelial adhesion molecules, ICAM-1 and VCAM-1, is linked to protein kinase $C$ activation. Scand J Immunol. 1992;36(2):159-65.

67. Mark KS, Trickler WJ, Miller DW. Tumor necrosis factor-alpha induces cyclooxygenase-2 expression and prostaglandin release in brain microvesse endothelial cells. J Pharmacol Exp Ther. 2001;297(3):1051-8.

68. Rask-Madsen C, et al. Tumor necrosis factor-alpha inhibits insulin's stimulating effect on glucose uptake and endothelium-dependent vasodilation in humans. Circulation. 2003:108(15):1815-21.

69. Moe GW, et al. In vivo TNF-alpha inhibition ameliorates cardiac mitochondrial dysfunction, oxidative stress, and apoptosis in experimental heart failure. Am J Physiol Heart Circ Physiol. 2004;287(4):H1813-20.

70. Bissonnette $\mathrm{R}$, et al. Effects of the tumor necrosis factor-alpha antagonist adalimumab on arterial inflammation assessed by positron emission tomography in patients with psoriasis: results of a randomized controlled trial. Circ Cardiovasc Imaging. 2013;6(1):83-90.

71. Pina $T$, et al. Anti-tumor necrosis factor-alpha therapy improves endothelial function and arterial stiffness in patients with moderate to severe psoriasis: a 6-month prospective study. J Dermatol. 2016;43(11):1267-72.

72. Hurlimann D, et al. Anti-tumor necrosis factor-alpha treatment improves endothelial function in patients with rheumatoid arthritis. Circulation. 2002; 106(17):2184-7.

73. Chung ES, et al. Randomized, double-blind, placebo-controlled, pilot trial of infliximab, a chimeric monoclonal antibody to tumor necrosis factor-alpha, in patients with moderate-to-severe heart failure: results of the anti-TNF Therapy Against Congestive Heart Failure (ATTACH) trial. Circulation. 2003; 107(25):3133-40

74. Ridker PM, et al. Antiinflammatory Therapy with Canakinumab for Atherosclerotic Disease. N Engl J Med. 2017;377(12):1119-31.

75. Everett BM, et al. Anti-inflammatory therapy with canakinumab for the prevention of hospitalization for heart failure. Circulation. 2019;139(10):128999.

76. Ridker PM, et al. Residual inflammatory risk associated with interleukin-18 and interleukin- 6 after successful interleukin-1 beta inhibition with canakinumab: further rationale for the development of targeted anticytokine therapies for the treatment of atherothrombosis. Eur Heart J. 2020; 41(23):2153-63.

77. Morisaki N, et al. New indices of ischemic heart disease and aging: Studies on the serum levels of soluble intercellular adhesion molecule-1 (ICAM-1) and soluble vascular cell adhesion molecule-1 (VCAM-1) in patients with hypercholesterolemia and ischemic heart disease. Atherosclerosis. 1997; 131(1):43-8

78. Edlinger $C$, et al. Disease-specific characteristics of vascular cell adhesion molecule-1 levels in patients with peripheral artery disease. Heart Vessel. 2019:34(6):976-83.

79. Blann AD, et al. Circulating ICAM-1 and VCAM-1 in peripheral artery disease and hypercholesterolaemia: relationship to the location of atherosclerotic disease, smoking, and in the prediction of adverse events. Thromb Haemost. 1998;79(6):1080-5.

80. Pradhan AD, Rifai N, Ridker PM. Soluble intercellular adhesion molecule-1, soluble vascular adhesion molecule-1, and the development of symptomatic peripheral arterial disease in men. Circulation. 2002;106(7):820-5.

81. Lin QY, et al. Pharmacological blockage of ICAM-1 improves angiotensin IIinduced cardiac remodeling by inhibiting adhesion of LFA-1(+) monocytes. Am J Phys Heart Circ Phys. 2019;317(6):H1301-11.

82. Karnik SS, et al. International Union of Basic and Clinical Pharmacology. XCIX. Angiotensin receptors: interpreters of pathophysiological angiotensinergic stimuli [corrected]. Pharmacol Rev. 2015;67(4):754-819.

83. Wang MY, Shah AM. Age-associated pro-inflammatory remodeling and functional phenotype in the heart and large arteries. J Mol Cell Cardiol. 2015;83:101-11. 
84. Aroor AR, et al. The role of tissue Renin-Angiotensin-aldosterone system in the development of endothelial dysfunction and arterial stiffness. Front Endocrinol (Lausanne). 2013;4:161.

85. Ferder $\mathrm{L}$, et al. Biomolecular changes in the aging myocardium - the effect of enalapril. Am J Hypertens. 1998;11(11):1297-304.

86. Benigni $A$, et al. Variations of the angiotensin II type 1 receptor gene are associated with extreme human longevity. Age. 2013;35(3):993-1005.

87. Campbell DJ, et al. Angiotensin peptides in spontaneously hypertensive and normotensive Donryu rats. Hypertension. 1995;25(5):928-34.

88. Duggan J, et al. Effects of aging and hypertension on plasma angiotensin-li and platelet angiotensin-II receptor density. Am J Hypertens. 1992;5(10): 687-93.

89. Li J, et al. An overview of osteocalcin progress. J Bone Miner Metab. 2016; 34(4):367-79.

90. Zoch ML, Clemens TL, Riddle RC. New insights into the biology of osteocalcin. Bone. 2016;82:42-9.

91. Jung KY, et al. Age- and sex-specific association of circulating osteocalcin with dynamic measures of glucose homeostasis. Osteoporos Int. 2016;27(3): 1021-9.

92. Seidu S, Kunutsor SK, Khunti K. Association of circulating osteocalcin with cardiovascular disease and intermediate cardiovascular phenotypes: systematic review and meta-analysis. Scand Cardiovasc J. 2019;53(6):286-95.

93. Kanazawa I, et al. Serum osteocalcin level is associated with glucose metabolism and atherosclerosis parameters in type 2 diabetes mellitus. J Clin Endocrinol Metab. 2009:94(1):45-9.

94. Kim HL, Kim SH. Pulse wave velocity in atherosclerosis. Front Cardiovasc Med. 2019;6:41.

95. Khrimian L, et al. Gpr158 mediates osteocalcin's regulation of cognition. J Exp Med. 2017;214(10):2859-73.

96. Mera P, et al. Osteocalcin Signaling in Myofibers Is Necessary and Sufficient for Optimum Adaptation to Exercise. Cell Metab. 2016;23(6):1078-92.

97. Mera P, et al. Osteocalcin is necessary and sufficient to maintain muscle mass in older mice. Molecular Metabolism. 2016;5(10):1042-7.

98. Smith $\mathrm{C}$, et al. Osteocalcin and its forms across the lifespan in adult men. Bone. 2020;130.

99. Dirckx N, et al. The role of osteoblasts in energy homeostasis. Nat Rev Endocrinol. 2019;15(11):651-65.

100. De Toni L, et al. Osteocalcin: a protein hormone connecting metabolism, bone and testis function. Protein Pept Lett. 2020;27(12):1268-75.

101. Sadek NB, et al. The potential role of undercarboxylated osteocalcin upregulation in microvascular insufficiency in a rat model of diabetic cardiomyopathy. J Cardiovasc Pharmacol Ther. 2020;25(1):86-97.

102. Diegel $C R$, et al. An osteocalcin-deficient mouse strain without endocrine abnormalities. PLoS Genet. 2020;16(5):e1008361.

103. Moriishi T, et al. Osteocalcin is necessary for the alignment of apatite crystallites, but not glucose metabolism, testosterone synthesis, or muscle mass. PLoS Genet. 2020;16(5):e1008586.

104. Tacey A, et al. Association between circulating osteocalcin and cardiometabolic risk factors following a 4-week leafy green vitamin K-rich diet. Ann Nutr Metab. 2020;76(5):361-7.

105. Liu ZX, et al. Serum Metrnl is associated with the presence and severity of coronary artery disease. J Cell Mol Med. 2019;23(1):271-80.

106. Wang K, et al. Serum levels of Meteorin-like (Metrnl) are increased in patients with newly diagnosed type 2 diabetes mellitus and are associated with insulin resistance. Med Sci Monit. 2019;25:2337-43.

107. Chung HS, et al. Implications of circulating Meteorin-like (Metrnl) level in human subjects with type 2 diabetes. Diabetes Res Clin Pract. 2018;136:1007.

108. El-Ashmawy HM, et al. Association of low serum Meteorin like (Metrnl) concentrations with worsening of glucose tolerance, impaired endothelial function and atherosclerosis. Diabetes Res Clin Pract. 2019;150:57-63.

109. AlKhairi l, et al. Increased expression of Meteorin-like hormone in type 2 diabetes and obesity and its association with irisin. Cells. 2019:8(10).

110. Lee $\mathbf{J H}$, et al. Serum Meteorin-like protein levels decreased in patients newly diagnosed with type 2 diabetes. Diabetes Res Clin Pract. 2018;135:7-10.

111. Zheng SL, et al. Evaluation of two commercial enzyme-linked immunosorbent assay kits for the detection of human circulating Metrnl. Chem Pharm Bull (Tokyo). 2018;66(4):391-8.

112. Wu Q, et al. Circulating Meteorin-like levels in patients with type 2 diabetes mellitus: a meta-analysis. Curr Pharm Des. 2020;26(44):5732-8.
113. Rao RR, et al. Meteorin-like Is a hormone that regulates immune-adipose interactions to increase beige fat thermogenesis. Cell. 2014;157(6):1279-91.

114. Lee JO, et al. The myokine meteorin-like (metrnl) improves glucose tolerance in both skeletal muscle cells and mice by targeting AMPK alpha 2 . FEBS J. 2020;287(10):2087-104.

115. Oi Q et al. Metrnl deficiency decreases blood HDL cholesterol and increases blood triglyceride. Acta Pharmacol Sin. 2020;41(12):1568-75.

116. Hu C, et al. Meteorin-like protein attenuates doxorubicin-induced cardiotoxicity via activating CAMP/PKA/SIRT1 pathway. Redox Biol. 2020;37.

117. Hu W, Wang R, Sun B. Meteorin-like ameliorates beta cell function by inhibiting beta cell apoptosis of and promoting beta cell proliferation via activating the WNT/beta-catenin pathway. Front Pharmacol. 2021;12:627147.

118. Baht GS, et al. Meteorin-like facilitates skeletal muscle repair through a Stat3/ IGF-1 mechanism (vol 2, pg 278, 2020). Nature Metabolism. 2020;2(8):794.

119. Sousa-Victor $P$, et al. MANF regulates metabolic and immune homeostasis in ageing and protects against liver damage. Nature Metabolism. 2019;1(2): 276-90.

120. Wu T, et al. Feeding-induced hepatokine, Manf, ameliorates diet-induced obesity by promoting adipose browning via p38 MAPK pathway. J Exp Med. 2021:218(6)

121. Lindahl $M$, et al. MANF is indispensable for the proliferation and survival of pancreatic beta cells. Cell Rep. 2014;7(2):366-75.

122. Hakonen $\mathrm{E}$, et al. MANF protects human pancreatic beta cells against stressinduced cell death. Diabetologia. 2018;61(10):2202-14.

123. Xu WL, et al. Mesencephalic astrocyte-derived neurotrophic factor (MANF) protects against neuronal apoptosis via activation of Akt/MDM2/p53 signaling pathway in a rat model of intracerebral hemorrhage. Front $\mathrm{Mol}$ Neurosci. 2018;11.

124. Tadimalla A, et al. Mesencephalic astrocyte-derived neurotrophic factor is an ischemia-inducible secreted endoplasmic reticulum stress response protein in the heart. Circ Res. 2008;103(11):1249-58.

125. Arrieta A, et al. Mesencephalic astrocyte?derived neurotrophic factor is an ER-resident chaperone that protects against reductive stress in the heart. Biol Chem. 2020:295(22):7566-83.

126. Shen $Y$, et al. Serum FGF21 Is Associated with future cardiovascular events in patients with coronary artery disease. Cardiology. 2018;139(4):212-8.

127. Li HT, et al. Fibroblast growth factor 21 levels are increased in nonalcoholic fatty liver disease patients and are correlated with hepatic triglyceride. J Hepatol. 2010;53(5):934-40.

128. Hanks LJ, et al. Circulating levels of fibroblast growth factor-21 increase with age independently of body composition indices among healthy individuals. J Clin Transl Endocrinol. 2015:2(2):77-82.

129. Taniguchi $H$, et al. Endurance exercise reduces hepatic fat content and serum fibroblast growth factor 21 levels in elderly men. J Clin Endocrinol Metab. 2016;101(1):190-7.

130. Sanchis-Gomar F, et al. A preliminary candidate approach identifies the combination of chemerin, fetuin-A, and fibroblast growth factors 19 and 21 as a potential biomarker panel of successful aging. Age. 2015:37(3).

131. Villarroya J, et al. Aging is associated with increased FGF21 levels but unaltered FGF21 responsiveness in adipose tissue. Aging Cell. 2018:17(5).

132. Kharitonenkov A, et al. FGF-21 as a novel metabolic regulator. J Clin Investig. 2005;115(6):1627-35.

133. Coskun T, et al. Fibroblast Growth Factor 21 Corrects obesity in mice. Endocrinology. 2008;149(12):6018-27.

134. Zhang $Y$, et al. The starvation hormone, fibroblast growth factor-21, extends lifespan in mice. Elife. 2012;1.

135. Fang $H$, et al. FGF21 prevents low-protein diet-induced renal inflammation in aged mice. Am J Physiol Renal Physiol. 2021;321(3):F356-68.

136. Kuroda M, et al. Peripherally derived FGF21 promotes remyelination in the central nervous system. J Clin Invest. 2017;127(9):3496-509.

137. Charles ED, et al. Pegbelfermin (BMS-986036), PEGylated FGF21, in Patients with Obesity and Type 2 Diabetes: Results from a Randomized Phase 2 Study. Obesity. 2019;27(1):41-9.

138. Gaich G, et al. The effects of LY2405319, an FGF21 analog, in obese human subjects with type 2 diabetes. Cell Metab. 2013;18(3):333-40.

139. Dong JQ, et al. Pharmacokinetics and pharmacodynamics of PF-05231023, a novel long-acting FGF21 mimetic, in a first-in-human study. Br J Clin Pharmacol. 2015:80(5):1051-63. 
140. Baccarelli A, et al. Activin A serum levels and aging of the pituitary-gonadal axis: a cross-sectional study in middle-aged and elderly healthy subjects. Exp Gerontol. 2001;36(8):1403-12.

141. Peng LN, et al. Association between serum activin A and metabolic syndrome in older adults: potential of activin A as a biomarker of cardiometabolic disease. Exp Gerontol. 2018;111:197-202.

142. Kuo CS, et al. Increased activin A levels in prediabetes and association with carotid intima-media thickness: a cross-sectional analysis from I-Lan Longitudinal Aging Study. Sci Rep. 2018;8.

143. Bian $\mathrm{XH}$, et al. Senescence marker activin $\mathrm{A}$ is increased in human diabetic kidney disease: association with kidney function and potential implications for therapy. BMJ Open Diabetes Res Care. 2019:7(1).

144. Polyzos SA, et al. Activin A and follistatin in patients with nonalcoholic fatty liver disease. Metabolism. 2016;65(10):1550-8.

145. Roh JD, et al. Activin type II receptor signaling in cardiac aging and heart failure. Sci Transl Med. 2019:11(482).

146. Vanhoutte $F$, et al. Pharmacokinetics and pharmacodynamics of garetosmab (anti-activin A): results from a first-in-human phase 1 study. J Clin Pharmacol. 2020;60(11):1424-31.

147. Muller DC, et al. Insulin response during the oral glucose tolerance test: the role of age, sex, body fat and the pattern of fat distribution. Aging (Milano). 1996;8(1):13-21.

148. Chang AM, Halter JB. Aging and insulin secretion. Am J Physiol Endocrinol Metab. 2003;284(1):E7-E12.

149. Templeman NM, et al. Reduced circulating insulin enhances insulin sensitivity in old mice and extends lifespan. Cell Rep. 2017;20(2):451-63.

150. Belke DD, et al. Insulin signaling coordinately regulates cardiac size, metabolism, and contractile protein isoform expression. J Clin Investig. 2002;109(5):629-39.

151. Shimizu l, et al. Excessive cardiac insulin signaling exacerbates systolic dysfunction induced by pressure overload in rodents. J Clin Investig. 2010; 120(5):1506-14

152. Shimizu l, et al. p53-induced adipose tissue inflammation is critically involved in the development of insulin resistance in heart failure. Cell Metab. 2012;15(1):51-64

153. Hua YN, et al. Chronic akt activation accentuates aging-induced cardiac hypertrophy and myocardial contractile dysfunction: role of autophagy. Basic Res Cardiol. 2011;106(6):1173-91.

154. Shimizu I, Minamino T. Physiological and pathological cardiac hypertrophy J Mol Cell Cardiol. 2016;97:245-62.

155. Packer M. Potentiation of insulin signaling contributes to heart failure in type 2 diabetes: a hypothesis supported by both mechanistic studies and clinical trials. JACC Basic Transl Sci. 2018;3(3):415-9.

156. Juul $A$, et al. Serum insulin-like growth factor-l in 1030 healthy-children, adolescents, and adults - relation to age, sex, stage of puberty, testicular size, and body-mass index. J Clin Endocrinol Metab. 1994;78(3):744-52.

157. Zhang WB, et al. Insulin-like growth factor-1 and IGF binding proteins predict all-cause mortality and morbidity in older adults. Cells. 2020:9(6).

158. Toth $\mathrm{P}$, et al. IGF-1 deficiency impairs neurovascular coupling in mice: implications for cerebromicrovascular aging. Aging Cell. 2015;14(6):1034-44.

159. Bailey-Downs LC, et al. Liver-specific knockdown of IGF-1 decreases vascular oxidative stress resistance by impairing the Nrf2-dependent antioxidant response: a novel model of vascular aging. J Gerontol A Biol Sci Med Sci. 2012;67(4):313-29.

160. Xu XH, Hueckstaedt LK, Ren J. Deficiency of insulin-like growth factor attenuates aging-induced changes in hepatic function: role of autophagy. J Hepatol. 2013;59(2):308-17

161. Holzenberger $M$, et al. IGF-1 receptor regulates lifespan and resistance to oxidative stress in mice. Nature. 2003;421(6919):182-7.

162. Shiojima I, et al. Disruption of coordinated cardiac hypertrophy and angiogenesis contributes to the transition to heart failure. J Clin Investig. 2005;115(8):2108-18

163. Izumiya $Y$, et al. Fast/glycolytic muscle fiber growth reduces fat mass and improves metabolic parameters in obese mice. Cell Metab. 2008;7(2):159-72.

164. Xia J, et al. Correlation of increased plasma osteoprotegerin and cardiovascular risk factors in patients with adult growth hormone deficiency. Int J Clin Exp Med. 2015;8(3):3184-92.

165. Colao A, et al. Improved cardiovascular risk factors and cardiac performance after 12 months of growth hormone $(\mathrm{GH})$ replacement in young adult patients with GH deficiency. J Clin Endocrinol Metab. 2001;86(5):1874-81.
166. Molitch ME, et al. Evaluation and treatment of adult growth hormone deficiency: an Endocrine Society clinical practice guideline. J Clin Endocrinol Metab. 2011;96(6):1587-609.

167. Lange $\mathrm{KHW}$, et al. GH administration changes myosin heavy chain isoforms in skeletal muscle but does not augment muscle strength or hypertrophy, either alone or combined with resistance exercise training in healthy elderly men. J Clin Endocrinol Metab. 2002;87(2):513-23.

168. Blackman MB, et al. Growth hormone and sex steroid administration in healthy aged women and men - a randomized controlled trial. JAMA. 2002; 288(18):2282-92

169. Marcus $\mathrm{R}$, et al. Effects of short-term administration of recombinant human growth-hormone to elderly people. J Clin Endocrinol Metab. 1990;70(2):519-27.

170. Papadakis MA, et al. Growth hormone replacement in healthy older men improves body composition but not functional ability. Ann Intern Med. 1996;124(8):708.

171. Harman SM, Blackman MR. Use of growth hormone for prevention or treatment of effects of aging. J Gerontol A Biol Sci Med Sci. 2004;59(7):652-8.

172. Swerdlow AJ, et al. Risk of cancer in patients treated with human pituitary growth hormone in the UK, 1959-85: a cohort study. Lancet. 2002;360(9329): 273-7.

173. Perls T, Reisman NR, Olshansky SJ. Provision or distribution of growth hormone for "antiaging": clinical and legal issues. JAMA. 2005;294(16): 2086-90.

174. Gimpl G, Fahrenholz F. The oxytocin receptor system: structure, function, and regulation. Physiol Rev. 2001;81(2):629-83.

175. Plasencia $\mathrm{G}$, et al. Plasma oxytocin and vasopressin levels in young and older men and women: functional relationships with attachment and cognition. Psychoneuroendocrinology. 2019;110.

176. Kunitake $Y$, et al. Serum oxytocin levels and logical memory in older people in rural Japan. J Geriatr Psychiatry Neurol. 2021;34(2):156-61.

177. Elabd C, et al. Oxytocin is an age-specific circulating hormone that is necessary for muscle maintenance and regeneration. Nat Commun. 2014;5.

178. Zhang $\mathrm{H}$, et al. Treatment of obesity and diabetes using oxytocin or analogs in patients and mouse models. PLoS One. 2013:8(6)

179. Luo, D., et al., Oxytocin promotes hepatic regeneration in elderly mice. Iscience, 2021. 24(2)

180. Barraza JA, et al. Effects of a 10-Day oxytocin trial in older adults on health and well-being. Exp Clin Psychopharmacol. 2013;21(2):85-92.

181. Svartberg J, et al. The associations of age, lifestyle factors and chronic disease with testosterone in men: the Tromso Study. Eur J Endocrinol. 2003; 149(2):145-52.

182. Barrettconnor $E_{1}$ Khaw KT. Endogenous sex-hormones and cardiovasculardisease in men - a prospective population-based study. Circulation. 1988; 78(3):539-45.

183. Khaw KT, et al. Endogenous testosterone and mortality due to all causes, cardiovascular disease, and cancer in men: European prospective investigation into cancer in Norfolk (EPIC-Norfolk) prospective population study. Circulation. 2007;116(23):2694-701.

184. Smith GD, et al. Cortisol, testosterone, and coronary heart disease prospective evidence from the Caerphilly study. Circulation. 2005;112(3): $332-40$

185. Jankowska EA, et al. Anabolic deficiency in men with chronic heart failure prevalence and detrimental impact on survival. Circulation. 2006;114(17): 1829-37.

186. Oh JY, et al. Endogenous sex hormones predict the development of type 2 diabetes in older men and women: the Rancho Bernardo study. Diabetes. 2001;50:A75-6.

187. Baillargeon and Mansi, Trends in androgen prescribing in the United States, 2001 to 2011 (vol 173, pg 1465, 2013). JAMA 173(15): p. 1477-1477.

188. Budoff MJ, et al. Testosterone treatment and coronary artery plaque volume in older men with low testosterone. JAMA. 2017:317(7):708-16.

189. Basaria S, et al. Adverse events associated with testosterone administration. N Engl J Med. 2010;363(2):109-22.

190. Navarro-Penalver M, et al. Testosterone replacement therapy in deficient patients with chronic heart failure: a randomized double-blind controlled pilot study. J Cardiovasc Pharmacol Ther. 2018;23(6):543-50.

191. Malkin CJ, et al. Testosterone therapy in men with moderate severity heart failure: a double-blind randomized placebo controlled trial. Eur Heart J. 2006;27(1):57-64. 
192. Resnick SM, et al. Testosterone treatment and cognitive function in older men with low testosterone and age-associated memory impairment. JAMA. 2017;317(7):717-27.

193. Snyder PJ, et al. Effects of testosterone treatment in older men. N Engl J Med. 2016;374(7):611-24.

194. Storer TW, et al. Effects of testosterone supplementation for 3 years on muscle performance and physical function in older men. J Clin Endocrinol Metab. 2017;102(2):583-93.

195. Walsh JP, Kitchens AC. Testosterone therapy and cardiovascular risk. Trends Cardiovasc Med. 2015;25(3):250-7.

196. MacDonell SO, et al. Vitamin D status and its predictors in New Zealand aged-care residents eligible for a government-funded universal vitamin D supplementation programme. Public Health Nutr. 2016;19(18):3349-60.

197. Ginde AA, et al. High-dose monthly vitamin D for Prevention of acute respiratory infection in older long-term care residents: a randomized clinical trial. J Am Geriatr Soc. 2017;65(3):496-503.

198. Anderson $J$, et al. Relation of vitamin D deficiency to cardiovascular risk factors, disease status, and incident events in a general healthcare population. Am J Cardiol. 2010;106(7):963-8.

199. Seker T, et al. Lower serum 25-hydroxyvitamin D level is associated with impaired myocardial performance and left ventricle hypertrophy in newly diagnosed hypertensive patients. Anatol J Cardiol. 2015;15(9):744-50.

200. Polat V, et al. Low vitamin D status associated with dilated cardiomyopathy. Int J Clin Exp Med. 2015;8(1):1356-62.

201. Chen S, et al. Cardiomyocyte-specific deletion of the vitamin D receptor gene results in cardiac hypertrophy. Circulation. 2011;124(17):1838-47.

202. Pittas AG, et al. Vitamin D supplementation and prevention of type 2 diabetes. N Engl J Med. 2019;381(6):520-30.

203. Bischoff-Ferrari HA, et al. Effect of vitamin D supplementation, omega-3 fatty acid supplementation, or a strength-training exercise program on clinical outcomes in older adults the DO-HEALTH randomized clinical trial. JAMA. 2020:324(18):1855-68.

204. Levis S, Gomez-Marin O. Vitamin D and physical function in sedentary older men. J Am Geriatr Soc. 2017:65(2):323-31.

205. Bischoff-Ferrari HA, et al. Monthly high-dose vitamin D treatment for the prevention of functional decline a randomized clinical trial. JAMA Intern Med. 2016;176(2):175-83.

206. Witham MD, et al. Vitamin D therapy to reduce blood pressure and left ventricular hypertrophy in resistant hypertension randomized, controlled trial. Hypertension. 2014:63(4):706-12.

207. Shea MK, et al. Vitamin K status, cardiovascular disease, and all-cause mortality: a participant-level meta-analysis of 3 US cohorts. Am J Clin Nutr. 2020;111(6):1170-7.

208. Shea MK, et al. Circulating vitamin $\mathrm{K}$ is inversely associated with incident cardiovascular disease risk among those treated for hypertension in the Health, Aging, and Body Composition Study (Health ABC). J Nutr. 2017; 147(5):888-95.

209. Shea MK, et al. Vitamin K, circulating cytokines, and bone mineral density in older men and women. Am J Clin Nutr. 2008:88(2):356-63.

210. Shea MK, et al. Vitamin K and vitamin D status: associations with inflammatory markers in the Framingham Offspring Study. Am J Epidemiol. 2008;167(3):313-20.

211. Shea MK, et al. Associations between vitamin K status and haemostatic and inflammatory biomarkers in community-dwelling adults: the Multi-Ethnic Study of Atherosclerosis. Thromb Haemost. 2014;112(3):438-44.

212. Zwakenberg SR, et al. Circulating Phylloquinone concentrations and risk of type 2 diabetes: a Mendelian randomization study. Diabetes. 2019;68(1):2205.

213. Lees JS, et al. Vitamin K status, supplementation and vascular disease: a systematic review and meta-analysis. Heart. 2019;105(12):938-45.

214. Brandenburg VM, et al. Slower progress of aortic valve calcification with vitamin $\mathrm{K}$ supplementation results from a prospective interventional proofof-concept study. Circulation. 2017;135(21):2081-3.

215. Beulens JWJ, et al. Dietary phylloquinone and menaquinones intakes and risk of type 2 diabetes. Diabetes Care. 2010;33(8):1699-705.

216. Witham MD, et al. Vitamin $\mathrm{K}$ supplementation to improve vascular stiffness in CKD: the K4Kidneys randomized controlled trial. J Am Soc Nephrol. 2020; 31(10):2434-45.

217. Bartstra JW, et al. Six months vitamin $\mathrm{K}$ treatment does not affect systemic arterial calcification or bone mineral density in diabetes mellitus 2. Eur J Nutr. 2021;60(3):1691-9.
218. Westerman $\mathrm{K}$, et al. Epigenome-wide association study reveals a molecular signature of response to phylloquinone (vitamin K1) supplementation. Epigenetics. 2020;15(8):859-70.

219. Olivieri F, et al. Age- and glycemia-related miR-126-3p levels in plasma and endothelial cells. Aging-Us. 2014;6(9):771-87.

220. Li P, et al. 17beta-Estradiol enhances vascular endothelial Ets-1/miR-126-3p expression: the possible mechanism for attenuation of atherosclerosis. J Clin Endocrinol Metab. 2017;102(2):594-603.

221. Zeng $P$, et al. ERK1/2 inhibition reduces vascular calcification by activating miR-126-3p-DKK1/LRP6 pathway. Theranostics. 2021;11(3):1129-46.

222. Ameling $\mathrm{S}$, et al. Associations of circulating plasma microRNAs with age, body mass index and sex in a population-based study. BMC Med Genet. 2015;8.

223. Luo $\mathrm{M}$, et al. Circulating miR-30c as a predictive biomarker of type 2 diabetes mellitus with coronary heart disease by regulating PAI-1NN interactions. Life Sci. 2019;239.

224. Olivieri F, et al. Age-related differences in the expression of circulating microRNAs: miR-21 as a new circulating marker of inflammaging. Mech Ageing Dev. 2012;133(11-12):675-85.

225. Mori MA, et al. Extracellular miRNAs: from biomarkers to mediators of physiology and disease. Cell Metab. 2019;30(4):656-73.

226. Olivieri $\mathrm{F}$, et al. Circulating miRNAs and miRNA shuttles as biomarkers: perspective trajectories of healthy and unhealthy aging. Mech Ageing Dev. 2017:165:162-70

227. Sha SJ, et al. Safety, tolerability, and feasibility of young plasma infusion in the Plasma for Alzheimer Symptom Amelioration Study: a randomized clinical trial. JAMA Neurol. 2019;76(1):35-40.

228. Pandika M. Looking to young blood to treat the diseases of aging. ACS Cent Sci. 2019;5(9):1481-4

229. Ikegami R, et al. Metabolomic analysis in heart failure. Circ J. 2018;82(1):10-6

230. Yeri $A$, et al. Metabolite profiles of healthy aging index are associated with cardiovascular disease in African Americans: the Health, Aging, and Body Composition Study. J Gerontol A Biol Sci Med Sci. 2019:74(1):68-72.

231. Ho, T.T., et al., Aged hematopoietic stem cells are refractory to bloodborne systemic rejuvenation interventions. J Exp Med, 2021. 218(7).

232. Ambrosi, T.H., et al., Aged skeletal stem cells generate an inflammatory degenerative niche. Nature, 2021. 597(7875): p. 256-+.

\section{Publisher's Note}

Springer Nature remains neutral with regard to jurisdictional claims in published maps and institutional affiliations.

Ready to submit your research? Choose BMC and benefit from:

- fast, convenient online submission

- thorough peer review by experienced researchers in your field

- rapid publication on acceptance

- support for research data, including large and complex data types

- gold Open Access which fosters wider collaboration and increased citations

- maximum visibility for your research: over $100 \mathrm{M}$ website views per year

At $\mathrm{BMC}$, research is always in progress.

Learn more biomedcentral.com/submission 